\title{
Massively parallel identification of causal variants underlying gene expression differences in a yeast cross
}

Kaushik Renganaath ${ }^{1, *}$, Rocky Cheung ${ }^{2, *}$, Laura Day ${ }^{3,4,5}$, Sriram Kosuri ${ }^{2}$, Leonid Kruglyak ${ }^{3,4,5, \dagger}$, Frank W. Albert ${ }^{1, *, \dagger}$

${ }^{1}$ Department of Genetics, Cell Biology, \& Development, University of Minnesota, Minneapolis, $\mathrm{MN}$

${ }^{2}$ Department of Chemistry \& Biochemistry, University of California, Los Angeles, CA

${ }^{3}$ Department of Human Genetics, University of California, Los Angeles, CA

${ }^{4}$ Department of Biological Chemistry, University of California, Los Angeles, CA

${ }^{5}$ Howard Hughes Medical Institute, University of California, Los Angeles, CA

*Joint first authors

$\dagger$ corresponding authors

\begin{abstract}
Sequence variation in regulatory DNA alters gene expression and shapes genetically complex traits. However, the identification of individual, causal regulatory variants is challenging. Here, we used a massively parallel reporter assay to measure the cis-regulatory consequences of 5,832 natural DNA variants in the promoters of 2,503 genes in the yeast Saccharomyces cerevisiae. We identified 451 causal variants, which underlie genetic loci known to affect gene expression. Several promoters harbored multiple causal variants. In five promoters, pairs of variants showed non-additive, epistatic interactions. Causal variants were enriched at conserved nucleotides, tended to have low derived allele frequency, and were depleted from promoters of essential genes, which is consistent with the action of negative selection. Causal variants were also enriched for alterations in transcription factor binding sites. Models integrating these features provided modest, but statistically significant, ability to predict causal variants. This work revealed a complex molecular basis for cis-acting regulatory variation.
\end{abstract}




\section{Introduction}

Individual genomes carry thousands of sequence differences in gene regulatory elements. Collectively, these variants contribute to variation in many phenotypic traits by altering the expression of one or multiple genes (Albert and Kruglyak, 2015). The presence of individual DNA variants that alter gene expression can be detected by mapping genomic regions called "expression quantitative trait loci" (eQTLs). Among these, "local" eQTLs are located close to or in the gene whose expression they influence. Eukaryotic species ranging from yeast to human carry large amounts of local regulatory variation (Brem et al., 2002; Hasin-Brumshtein et al., 2016; Heyne et al., 2014; Rockman et al., 2010; Stranger et al., 2005; West et al., 2006). In human populations, most genes are affected by one or multiple local eQTLs (GTEx Consortium et al., 2017). Similarly, in a cross between two genetically different yeast isolates, $74 \%$ of genes are influenced by local eQTLs (Albert et al., 2018). Most of these local eQTLs arise from DNA variants that perturb cis-acting regulatory mechanisms (Albert et al., 2018; Ronald et al., 2005). When such cis-acting variants are located in a gene's transcribed region, they may alter mRNA stability, splicing, polyadenylation, or regulation by RNA-binding proteins. Cis-acting variants in promoters or enhancers may alter the transcription of their target genes.

As a consequence of genetic linkage in experimental crosses (Albert et al., 2018) and linkage disequilibrium in outbred populations (GTEx Consortium et al., 2017; Kita et al., 2017), regions mapped as eQTLs almost always contain multiple sequence variants. Typically, it is assumed that most of these variants have no effect, obscuring the identity of one or a few causal variants in each eQTL (Figure 1). Although the causal variants in several local eQTLs have been identified (Chang et al., 2013; Claussnitzer et al., 2015; Lutz et al., 2019; Musunuru et al., 2010; Ronald et al., 2005), most causal variants remain unknown. Because of this lack of systematic information, many questions about local eQTLs remain open, including whether local eQTLs are typically caused by one or multiple variants, if multiple variants interact in a non-additive fashion, what evolutionary forces act on causal variants, which molecular mechanisms causal variants perturb, and whether it may ultimately be possible to combine the answers to these questions to construct models that can predict the consequences of regulatory variants from genome sequence.

Massively parallel reporter assays (MPRAs) have begun to make it possible to dissect regulatory activity of DNA sequences at scale (Kinney et al., 2010; Melnikov et al., 2012; Mulvey et al., 2020; Patwardhan et al., 2009). In these approaches, which have been applied in bacteria (Cambray et al., 2018; Kinney et al., 2010; Kosuri et al., 2013), yeast (Cuperus et al., 2017; Mogno et al., 2013; Sharon et al., 2012), flies (Gisselbrecht et al., 2013), zebrafish (Rabani et al., 2017), mouse tissues (Kwasnieski et al., 2014; Smith et al., 2013), and cultured human cells (Mulvey et al., 2020), pooled libraries of DNA oligos are placed next to or in a reporter gene and inserted into populations of cells. The activity of each oligo is then assayed in bulk by pooled high-throughput sequencing. MPRAs have been performed with synthesized libraries of designed oligos (Sharon et al., 2012), with fragmented genomic DNA (Arensbergen et al., 2019; Arnold et al., 2013; Wang et al., 2018), and with randomly generated DNA (Cuperus et al., 2017; de Boer et al., 2020; Rosenberg et al., 2015). MPRA readouts have included sequencing of either the oligos themselves (Arnold et al., 2013) or short barcodes that tag each oligo (Kwasnieski et al., 2012). MPRAs have quantified mRNA expression by sequencing cDNA (Kwasnieski et al., 2012) and protein expression based on "FACS-Seq" approaches in which cells are sorted into bins of increasing fluorescent reporter gene activity (Kinney et al., 2010; Matreyek et al., 2018; 
Sharon et al., 2012). MPRAs have been conducted using plasmid-borne reporters as well as reporters integrated into the genome (Inoue et al., 2017; Maricque et al., 2019; Mogno et al., 2013).

MPRAs have been used to probe DNA sequences for their ability to drive transcription (Arnold et al., 2013; Kheradpour et al., 2013; Wang et al., 2018), dissect the importance of individual bases in regulatory elements (Patwardhan et al., 2009), and examine the combined effects of multiple elements in regulatory "grammars" (Davis et al., 2020; Kosuri et al., 2013; Mogno et al., 2013; Sharon et al., 2012; Smith et al., 2013) in promoters (Kotopka and Smolke, 2020; Lubliner et al., 2015; Sharon et al., 2012; Weingarten-Gabbay et al., 2019), UTRs (Cuperus et al., 2017; Dvir et al., 2013; Rabani et al., 2017; Shalem et al., 2015) and enhancers (Arnold et al., 2013; Klein et al., 2019; Melnikov et al., 2012; Patwardhan et al., 2009). Other applications have assayed sequences that promote splicing (Cheung et al., 2019; Rosenberg et al., 2015), translation (Goodman et al., 2013; Weingarten-Gabbay et al., 2016), DNA methylation (Krebs et al., 2014) and RNA editing (Safra et al., 2017). More recently, MPRAs have identified individual human DNA variants that alter gene expression (Tewhey et al., 2016; Ulirsch et al., 2016) in studies ranging in scale from variants in specific regions implicated by genome-wide association studies for a given disease (Choi et al., 2019; Liu et al., 2017; Pashos et al., 2017; Vockley et al., 2015) to a genome-wide survey of nearly six million common single-nucleotide polymorphisms (Arensbergen et al., 2019). In spite of these successes, the size of the human genome, which harbors tens of millions of rare as well as common variants (Consortium, 2015), combined with a high degree of tissue-specificity in gene expression and the activity of regulatory DNA (GTEx Consortium et al., 2017; Inoue et al., 2019; Maricque et al., 2019) have complicated dissection of causal variants in local eQTLs. The compact gene regulatory regions of $S$. cerevisiae, combined with comprehensive eQTL maps (Albert et al., 2018), provide an excellent opportunity to study regulatory variants systematically.

Here, we used an MPRA to probe thousands of intergenic variants that differ between two yeast isolates. We identified 451 variants with significant cis-acting effects on mRNA expression. These causal variants underlie known local eQTLs. We found that individual local eQTLs can harbor multiple causal variants, including pairs of variants with non-additive, epistatic effects. Causal variants tended to alter transcription factor binding motifs and showed signs of evolving under negative selection. Combinations of these features predicted causal variants better than expected by chance, albeit with modest accuracy. 


\section{Results}

An MPRA to assay cis-regulatory variants in yeast promoters

At least half of the genes in the yeast genome are influenced by local eQTLs that segregate between the laboratory strain BY, a close relative of the genome reference strain S288C, and $\mathrm{RM}$, a vineyard isolate that is related to strains commonly used in wine making (Peter et al., 2018). Most of these eQTLs act in cis (Albert et al., 2018), making the BY and RM strains a rich reservoir for identifying causal cis-acting variants. Here, we studied DNA variants in yeast promoters, which we defined as the intergenic region upstream of the transcription start site of a given gene up to the coding region of the adjacent gene, for a maximum of 1,000 bases. These promoter regions differ between BY and RM at 11,768 single nucleotide variants (SNVs) and 2,442 insertion/deletion variants (indels) in 3,176 genes (Bloom et al., 2013).

To assay the effects of individual variants on gene expression, we designed an MPRA composed of two synthetic promoter libraries encoded by pooled oligonucleotides (Figure 1, Table 1, Table S1). The "TSS" library assayed all variants in the 144 nucleotides immediately upstream of the transcription start site (Pelechano et al., 2013), a region that is highly enriched for transcription factor binding sites (Lin et al., 2010). When multiple variants were present within this region for a given gene, we designed one sequence that carried the BY allele at all variants, one sequence that carried the RM allele at all variants, and a set of sequences that each carried the RM allele at a single variant. The "Upstream" library mostly assayed variants located further upstream of the transcription start site than those in the TSS library, using a pair of sequences that represented $144 \mathrm{bp}$ of genomic DNA centered on the given variant. By design, the TSS and Upstream libraries shared a subset of variants. Together, they assayed 7,005 unique variants $(5,758 \mathrm{SNVs}$ and 1,247 indels; Figure S1) in the promoters of 3,076 genes, with a median of two variants per gene (Figure S2). 


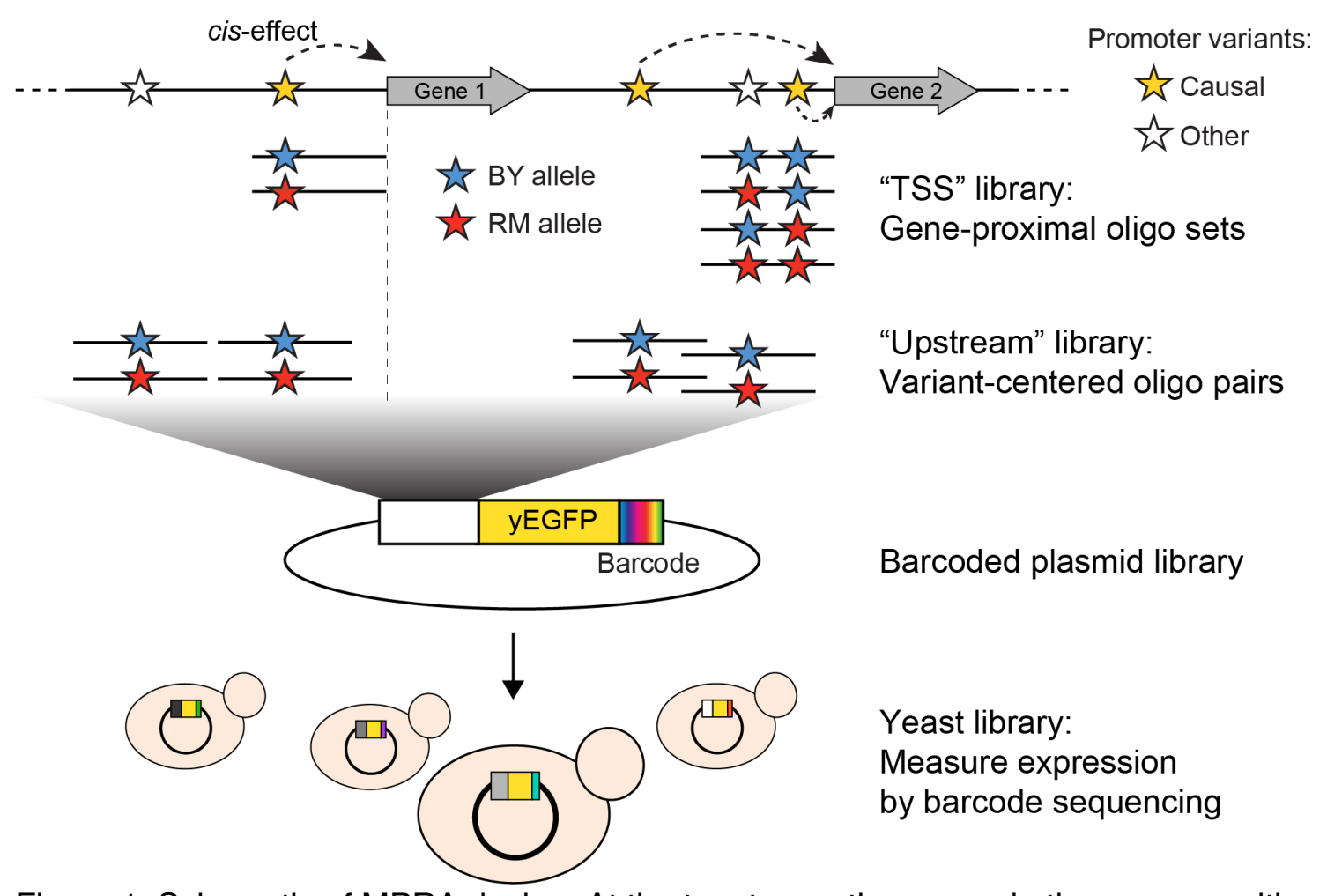

Figure 1: Schematic of MPRA design. At the top, two native genes in the genome with multiple promoter variants (stars) are shown. Below the two genes, the TSS and Upstream MPRA library designs are illustrated. The TSS library tests all variants within $144 \mathrm{bp}$ of the transcription start site (dashed vertical lines), while the Upstream library tests a subset of TSS variants along with variants located further away from the transcription start site.

Table 1 - Library design and representation in experiments

\begin{tabular}{|l|l|l|}
\hline Library & TSS & Upstream \\
\hline Designed oligos & 7,211 & 9,882 \\
\hline Variants in design & 3,645 & 4,547 \\
\hline Genes in design & 2,172 & 1,918 \\
\hline Oligos in finished library & 6,565 & 9,646 \\
\hline Barcodes & 9.2 million & 20 million \\
\hline Median barcodes per oligo & 590 & 1,008 \\
\hline Variants with data & 2,427 & 4,467 \\
\hline Genes with data & 1,429 & 1,824 \\
\hline Number of replicates & 12 & 6 \\
\hline
\end{tabular}


The synthesized oligo libraries were placed upstream of a yEGFP reporter gene (Sheff and Thorn, 2004) on a low-copy number yeast plasmid (Figure 1). Prior to adding the yEGFP gene, we added random barcodes with a length of 20 nucleotides downstream of the reporter gene (Figure $1 \&$ Figure S3). These barcodes were expressed as part of the 3' end of the reporter mRNA, such that barcode abundance provided a measure of gene expression driven by the given oligo. We used paired-end sequencing to map each barcode to the oligo it tagged (Figure S3). Most oligos were tagged by hundreds of barcodes (Table 1, Figure S4) to control for possible influences of the expressed barcodes on mRNA levels. The final plasmid libraries we used in our experiments contained more than $90 \%$ of the designed oligos (Table 1; see Methods and Figure S5 for a description of oligos not represented in the library). The libraries were transformed into the BY strain and grown in independent replicate cultures (Table 1). We grew each culture to late exponential phase, extracted mRNA and plasmid DNA from each culture, and sequenced barcodes (Figure S6) to a median depth of 46 million RNA reads (range 19-70 million) and 31 million DNA reads (range $14-84$ million) per sample (Table S2).

\section{Oligo expression is reproducible and reflects gene expression in the genome}

We conducted three analyses to assess the reliability of our data. First, we measured the reproducibility of oligo-driven reporter expression. We summed the RNA counts of all barcodes assigned to a given oligo (Table S3), divided them by the respective summed DNA counts to normalize for unequal library composition, and $\log _{2}$-transformed the resulting ratio. Spearman's rank correlation coefficients (rho) among pairs of replicates ranged from $0.79-0.90$ (median $=$ 0.83 ) in the Upstream library and from $0.55-0.93$ (median $=0.74$ ) in the TSS library (Figure S7A \& D).

Second, our two libraries included a common set of 200 oligos whose sequences we had sampled from a prior study (Sharon et al., 2012), allowing us to determine reproducibility between replicates, libraries, and with prior work. Median correlations between TSS and Upstream replicates (rho $=0.76$ ) were nearly as high as those between replicates within each library (TSS: 0.8, Upstream: 0.99; Figure S8). Further, the 200 oligos showed significant, positive correlations with their published expression levels (rho $\geq 0.4, \mathrm{p} \leq 1 \mathrm{e}-6$ ), in spite of experimental and design differences between studies (Figure S7B \& E).

Third, we asked if the promoter fragments in our plasmid libraries were able to recapitulate the expression of genes in their native genomic locations. To do so, we computed the average expression driven by all oligos extracted from the promoter region of a given gene. Although each oligo contained at most $150 \mathrm{bp}$ of promoter sequence on a plasmid, expression in both libraries correlated significantly ( $r h o \geq 0.23, \mathrm{p}<2.2 \mathrm{e}-16$ ) with the native mRNA levels of genes in the genome (Figure S7C \& F). In sum, our assay quantified the regulatory activity of promoter fragments in a manner that was reproducible within our study and when compared to earlier work, and that reflected the activity of native promoters in the genome.

\section{Identification of hundreds of cis-acting promoter variants}

To identify individual causal variants, we tested each promoter variant for its effect on reporter gene expression. We detected 166 variants with significant effects in the TSS library and 293 variants in the Upstream library at a false discovery rate (FDR) of 5\% (Table S4). The $\pi_{1}$ statistic 
(Storey and Tibshirani, 2003) computed across all variants suggested that at least 26\% and 31\% of variants had effects on gene expression in the TSS and Upstream libraries, respectively, even if these variants could not all be detected with individual significance. There were 451 unique variants that reached significance across the two partially overlapping libraries, out of 5,832 variants in the promoters of 2,503 genes that were available for testing (Figure 2A, Table S5).
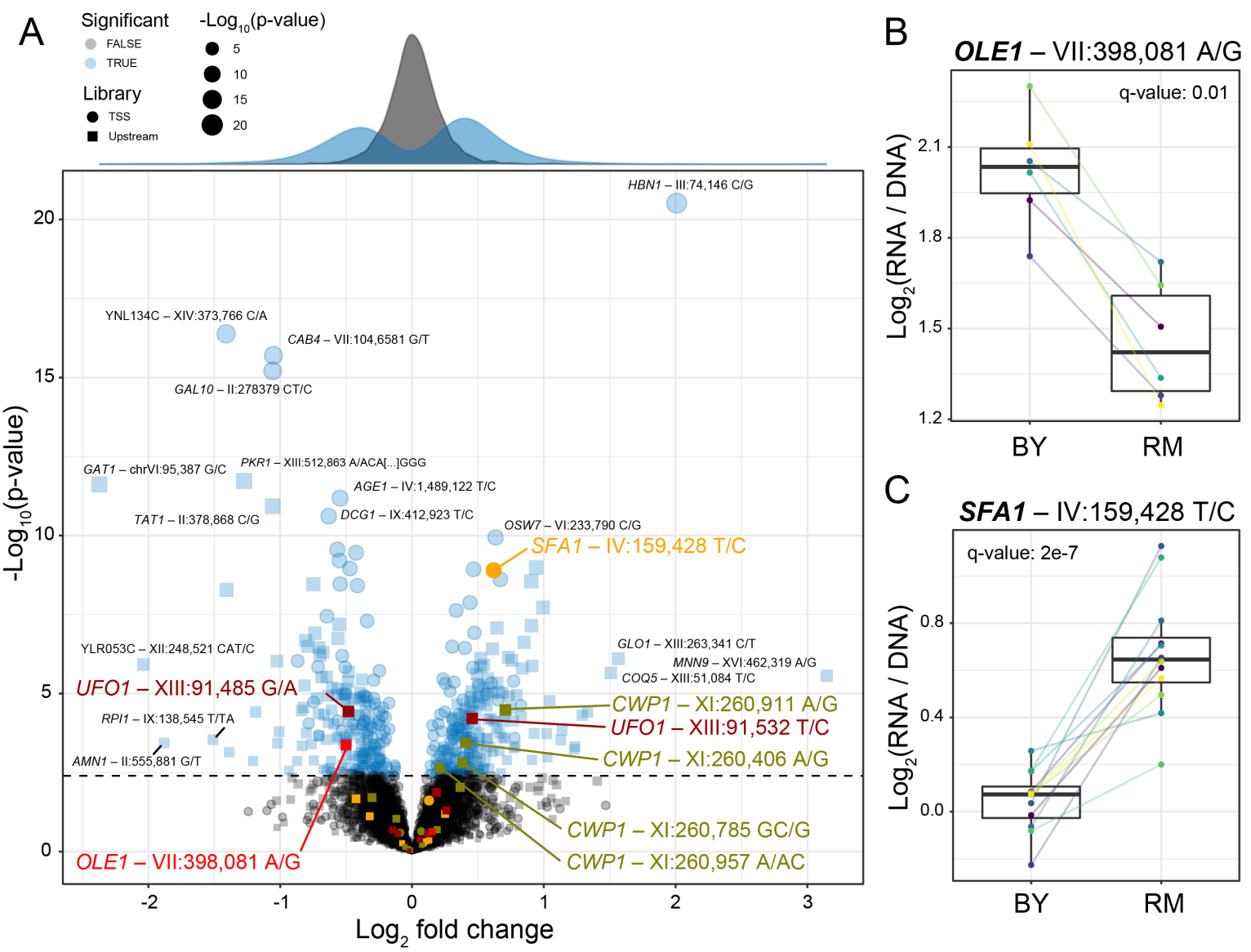

Figure 2: Identification of single causal variants. A) A scatterplot showing the effect size and significance for each variant. The genome-wide significance threshold is shown as a dashed horizontal line. Variants with the most significant effects, along with the genes they affect, are indicated. Variants and genes highlighted in color are described in the text. The histograms at the top shows the distribution of effect sizes for causal (blue) and non-causal (grey) variants. B) A variant in the promoter of OLE1 known to affect OLE1 expression has a significant effect in the Upstream MPRA. The figure shows expression values for oligos carrying the two alleles. Colored lines and dots indicate different biological replicate experiments. Boxplots show the median as thick line, with the box showing the $25^{\text {th }}$ and $75^{\text {th }}$ percentiles. Whiskers show the largest value no further than 1.5 times the inter-quartile range; points beyond this range are shown as individual points. $\mathrm{C}$ ) As in B) for a variant in the SFA1 promoter, which was detected in the TSS library.

As expected for natural variants, most had small effects on gene expression (Figure 2A). The median fold change between alleles was 1.4 -fold, and only 29 causal variants $(6 \%)$ altered expression by more than two-fold. 
Our MPRA assayed some variants multiple times in different sequence contexts, and we used this redundancy to assess the reproducibility of variant effects. First, 359 variants that reside in the intergenic region between two divergently expressed genes were tested twice in the same library, but in opposite orientation relative to the reporter gene (Figure S9A). Variants that were significant in at least one strand orientation were likely to also be significant in the other orientation (Fisher's exact test (FET): $\mathrm{p}=0.0003$, odds ratio $(\mathrm{OR})=7$ ). These significant variants also agreed well in the direction of variant effect, i.e. whether the RM allele drives higher or lower expression than the BY allele (FET: $p=0.007, \mathrm{OR}=6.1)$. Second, 527 variants were assayed in both the TSS and the Upstream libraries, where they were embedded in oligos that had the same strand orientation but differed in the exact window of DNA surrounding each variant (Figure S9B). Among these, variants that were significant in at least one library were likely to also be significant in the other $(\mathrm{FET} p=0.007, \mathrm{OR}=4)$, with significant directional agreement $(\mathrm{FET} \mathrm{p}=0.046, \mathrm{OR}=2.9)$. Thus, in spite of the small effects of natural sequence variants, our assay was able to reproducibly identify individual causal variants.

Our assay identified several known causal variants. For example, a variant in the promoter of the $O L E 1$ gene affects $O L E 1$ expression in cis and is likely to be the single causal variant in this promoter (Lutz et al., 2019). This variant was highly significant in the MPRA (Figure 2B), while a second variant in the $O L E 1$ promoter was not (Figure 2A).

In the promoter of the $S F A 1$ gene, the MPRA detected a single causal variant out of nine that were assayed (Figure 2A). The RM allele of the causal variant is also present in a strain used for bioethanol production (YJS329), where it has been proposed to increase $S F A 1$ expression by creating an Msn2/4 binding site (Maurer et al., 2017; Zheng et al., 2012). In our assay, this allele increased gene expression significantly (Figure 2C). Taken together, these results show that our MPRA reproducibly detected hundreds of individual cis-acting DNA variants.

\section{Local eQTLs can be caused by single or multiple causal variants}

The identity of causal variants in QTL regions is a major question in the genetics of complex traits. We asked if the variants identified by our MPRA underlie the many local eQTLs that segregate between the BY and RM strains. Specifically, we turned to local eQTLs mapped in 1,012 recombinant individuals obtained by crossing BY and RM (Albert et al., 2018). Because of genetic linkage in the cross, the effects of neighboring variants create one aggregated, spread-out signal of local variation at each gene. For 2,884 genes, these effects were strong enough to be detected as local eQTLs at genome-wide significance (Albert et al., 2018). We asked to what extent these local eQTLs can be explained by individual causal variants identified here (Table S6).

Initially, we considered all 2,300 genes with available data from both the cross and the MPRA, irrespective of whether their local effect had reached significance in the cross. Likewise, we summed the MPRA effects of all assayed variants for a given gene, irrespective of their significance. There was a significant correlation between local eQTL effects and summed MPRA effects ( rho $=0.1, p=1 \mathrm{e}-6)$. This overall correlation is likely degraded by noise in both datasets, in particular for small, non-significant effects. Therefore, we first restricted our analyses to variants with significant (5\% FDR) MPRA effects. The summed effects of these significant variants showed a stronger correlation with eQTL effects than did those of all variants (rho = $0.24, \mathrm{p}=5 \mathrm{e}-6)$. Next, to also avoid noise in the eQTL effect estimates, we further restricted the 
comparison to the 238 genes with strong local eQTLs - those with a LOD score of at least 50. This filter again improved the correlation with summed significant MPRA effects ( $r h o=0.47, p$ $=2 \mathrm{e}-5)$. These agreements show that, in aggregate, our MPRA successfully captured effects of variants that cause local eQTLs.
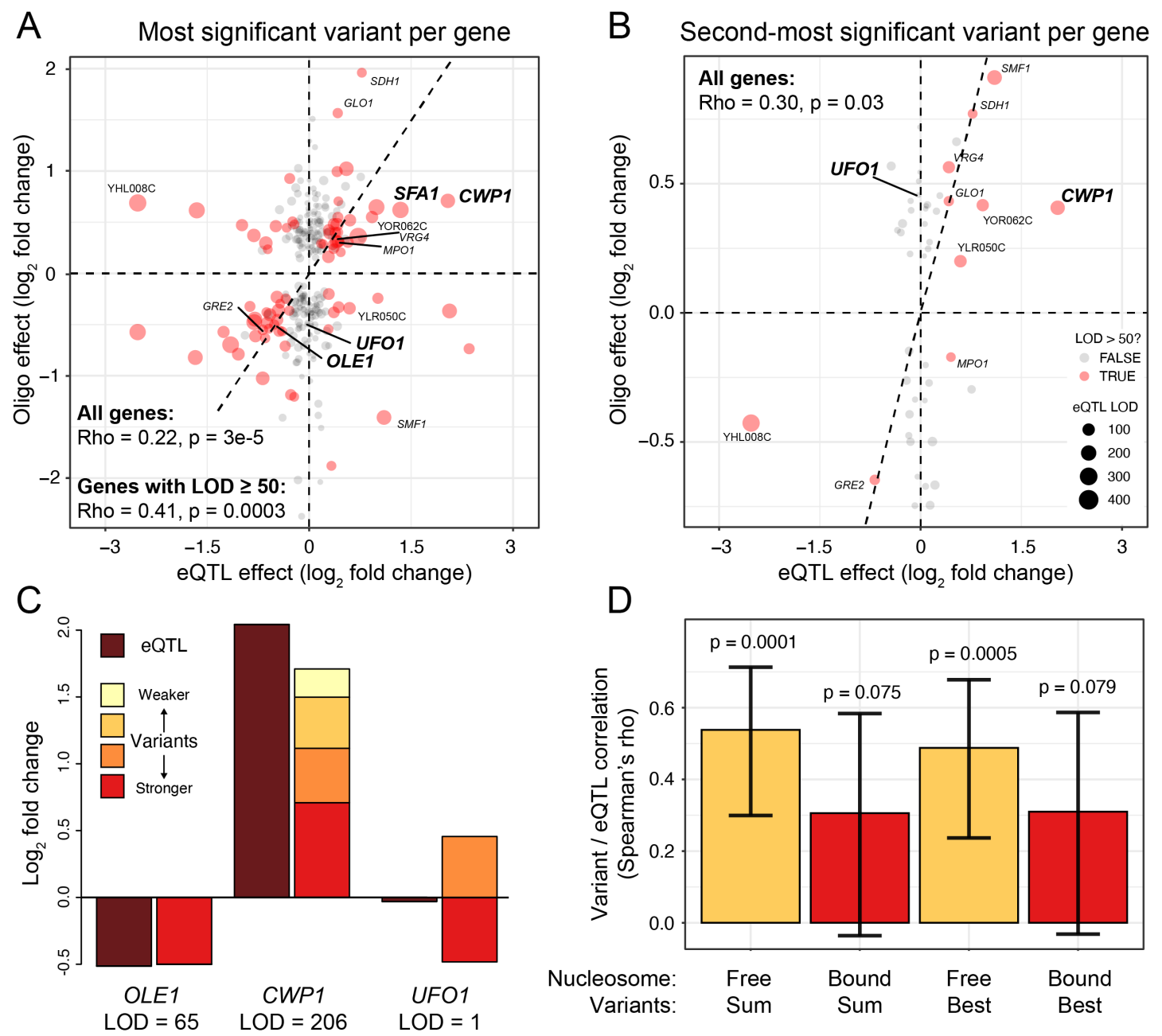

Figure 3: Comparison of variant effects to local eQTLs. A) Scatterplot showing the MPRA effect of the most significant causal variant per gene ( $y$-axis) versus the effect of the local eQTL (x-axis). Red dots indicate local eQTLs with a LOD score of at least 50 . Genes describes in the text and in panel $\mathrm{C}$ ) are highlighted in bold. Other genes also present in panel B) are indicated in regular font. The dashed diagonal shows the case of equal MPRA and local eQTL effects. Dashed horizontal and vertical lines indicate no effect. The panel only shows variants with a significant MPRA effect. B) As in A), but for the secondmost significant causal variant per gene. Note the different scale of the y axis between $A$ and B. C). Examples of summed MPRA effects of individual variants compared to the local eQTL for the given gene. D). Spearman correlation coefficients MPRA variants versus local eQTLs as a function of whether a variant is bound by a nucleosome in the genome. Significance of the correlation is indicated. Error bars show 95\% confidence intervals for the strength of the correlation. 
We asked whether single MPRA variants could account for local eQTLs. At each gene, we extracted the most significant variant among those with an FDR of $\leq 5 \%$. The effects of these single variants correlated with strong local eQTLs ( $\mathrm{rho}=0.41, \mathrm{p}=3 \mathrm{e}-4)$ and showed significant agreement between the direction of the effects of the variants and the eQTLs (FET: OR $=6.9, \mathrm{p}$ $=9 \mathrm{e}-5$; Figure 3A). For example, the MPRA effect for the single causal variant in the $O L E 1$ promoter (Lutz et al., 2019) recapitulated the magnitude of the OLE1 local eQTL almost perfectly (Figure 3A \& C). Thus, we identified individual causal variants that underlie local eQTLs.

QTL regions for organismal traits can harbor multiple causal variants (Mackay et al., 2009), but it is less clear whether QTLs for cellular traits such as gene expression have a similarly complex molecular basis. To test whether local eQTLs contain multiple causal variants, we considered, where available, the second most significant MPRA variant for each gene, if that variant was still significant at an FDR of 5\%. The effects of these second variants correlated with eQTL effects $($ rho $=0.3, p=0.03$; Figure 3B). Further, there were significant correlations between the number of nominally significant $(\mathrm{p}<0.05)$ MPRA variants identified for a gene and that gene's local eQTL LOD score $(r h o=0.12, p=0.003)$ and its absolute eQTL effect size $(r h o=0.14, p=3 e-$ 5). Thus, some local eQTLs are due to multiple causal promoter variants.

Some genes were affected by more than two causal variants. For example, we detected four causal variants at the $C W P 1$ gene (Figure 2A). At each of these variants, the RM allele increased expression, and their summed effects approximated that of the CWP1 local eQTL (Figure 3C).

Some genes had two significant variants with opposite direction of effect. For example, we detected two variants located 47 bases apart in the promoter of the UFO1 gene that had effects of similar magnitude but in opposite direction (Figure 2A). UFO1 does not have a significant local eQTL (Figure 3C), suggesting that this gene is influenced by two variants whose effects cancel each other out.

Together, these observations suggest that the molecular basis of local eQTLs spans a range of scenarios. Some local eQTLs are due to single causal variants, while others arise from joint effects of multiple causal variants. When multiple variants have effects in the same direction, they sum to create a stronger eQTL. When their effects are in the opposite directions, they may be invisible in a cross.

\section{The effects of individual variants can be influenced by nucleosome binding}

Our plasmid-based MPRA tested variants in a molecular context that differs from the native genomic context in two respects: in the DNA sequence beyond that present on the oligos and, potentially, in the chromatin state in which each variant is embedded. Specifically, nucleosomes influence gene expression (Han and Grunstein, 1988), and may mask or otherwise alter the effects of variants they bind (Rando and Winston, 2012; Zhu et al., 2018). We asked whether the effects of variants located in nucleosome-free regions in the genome (Brogaard et al., 2012) were better captured by our MPRA than those of nucleosome-bound variants. Indeed, the summed effects of significant variants in nucleosome-free regions correlated better with strong local eQTLs than those of nucleosome-bound variants, which showed no significant correlation (Figure 3D). A similar difference was seen for the single most significant MPRA variant (Figure 3D). This better agreement between the genome and the MPRA for the effects of variants in 
nucleosome-free regions would be expected if these variants are also not bound by nucleosomes on the plasmids, and are thus exposed to a molecular environment that resembles that in the genome. More broadly, this result suggests that nucleosome occupancy and chromatin state can alter the regulatory effects of genomic variants, consistent with MPRAs in human cells (Inoue et al., 2019; Maricque et al., 2019) and with the fact that many human local eQTLs vary among tissues and cell types (GTEx Consortium et al., 2017; Yao et al., 2020).

\section{Non-additive interactions among promoter variants}

The presence of multiple causal variants in single promoters raises the question of whether these variants have independent, additive effects or if the effects of some variants are modulated by the presence of the other variant(s) in a non-additive, epistatic interaction. To address this question, we made use of the fact that the TSS library included 342 variant pairs for which there were oligos representing all four combinations of the two alleles at the two variants. For each such variant pair, we tested whether the joint effect of both variants differed from the sum of their individual effects (Table S7).

There were five variant pairs that showed evidence for non-additive effects at an FDR of $\leq 20 \%$. While the $\pi_{1}$ statistic (Storey and Tibshirani, 2003) suggested that at least $34 \%$ of variant pairs have non-additive effects, the majority of these cases could not be detected at individual significance, presumably due to limited statistical power.

The five significant pairs showed a range of epistatic patterns (Figure $4 \&$ Figure S10). For example, the RM alleles at two variants upstream of $D A D 2$ did not have significant effects individually ( $\mathrm{p}>0.4$ compared to the oligo with two BY alleles), but when combined, the two $\mathrm{RM}$ alleles drove significantly higher expression $(\mathrm{p}=2 \mathrm{e}-6, \mathrm{FDR}=0.01 \%$; Figure 4$)$. RM carries a derived allele at each of these variants, indicated by the fact that the BY alleles are present in a strain from the Taiwanese clade of yeast isolates, which split early from other isolates (including BY and RM) during S. cerevisiae evolution (Peter et al., 2018). Both derived alleles are found at high and nearly identical frequencies in the yeast population $(\sim 74 \%)$, and the two variants, which are separated by only two nucleotides, show very high linkage disequilibrium $\left(D^{\prime}=0.999, \mathrm{r}^{2}=\right.$ 0.99). Thus, these two epistatic variants form a tightly linked haplotype that increases gene expression only when both RM alleles are present, perhaps because both variants are needed to create a binding site for a transcriptional activator.

The RM alleles at two SNVs upstream of RTT101 each reduced expression compared to the BY background (FDR $<0.1 \%$ ), but an oligo carrying both RM alleles reduced expression to a similar degree as either variant alone (Figure 4B). Both RM alleles are derived, and the two variants have very little recombination $\left(D^{\prime}=0.998\right)$. However, the two RM alleles do not form a common haplotype $\left(\mathrm{r}^{2}=0.08\right)$, likely because while the $\mathrm{RM}$ " $\mathrm{A}$ " allele at $352,322 \mathrm{bp}$ on chromosome $\mathrm{X}$ is present in $42 \%$ of yeast isolates, the RM " $G$ " allele at $352,304 \mathrm{bp}$ is much rarer, with a frequency of $6 \%$. These results suggest that a common promoter variant reduces the expression of RTT101. A second, much rarer variant has a similar effect in isolation, but its effect is obscured in the presence of the more common variant, perhaps because both variants abrogate binding of the same transcriptional activator. 
Together, these results show that cis-acting promoter variants can influence gene expression in a non-additive fashion. Such epistatic effects may be widespread, but the resultant deviations from additive expectations are often small, making their systematic detection challenging.
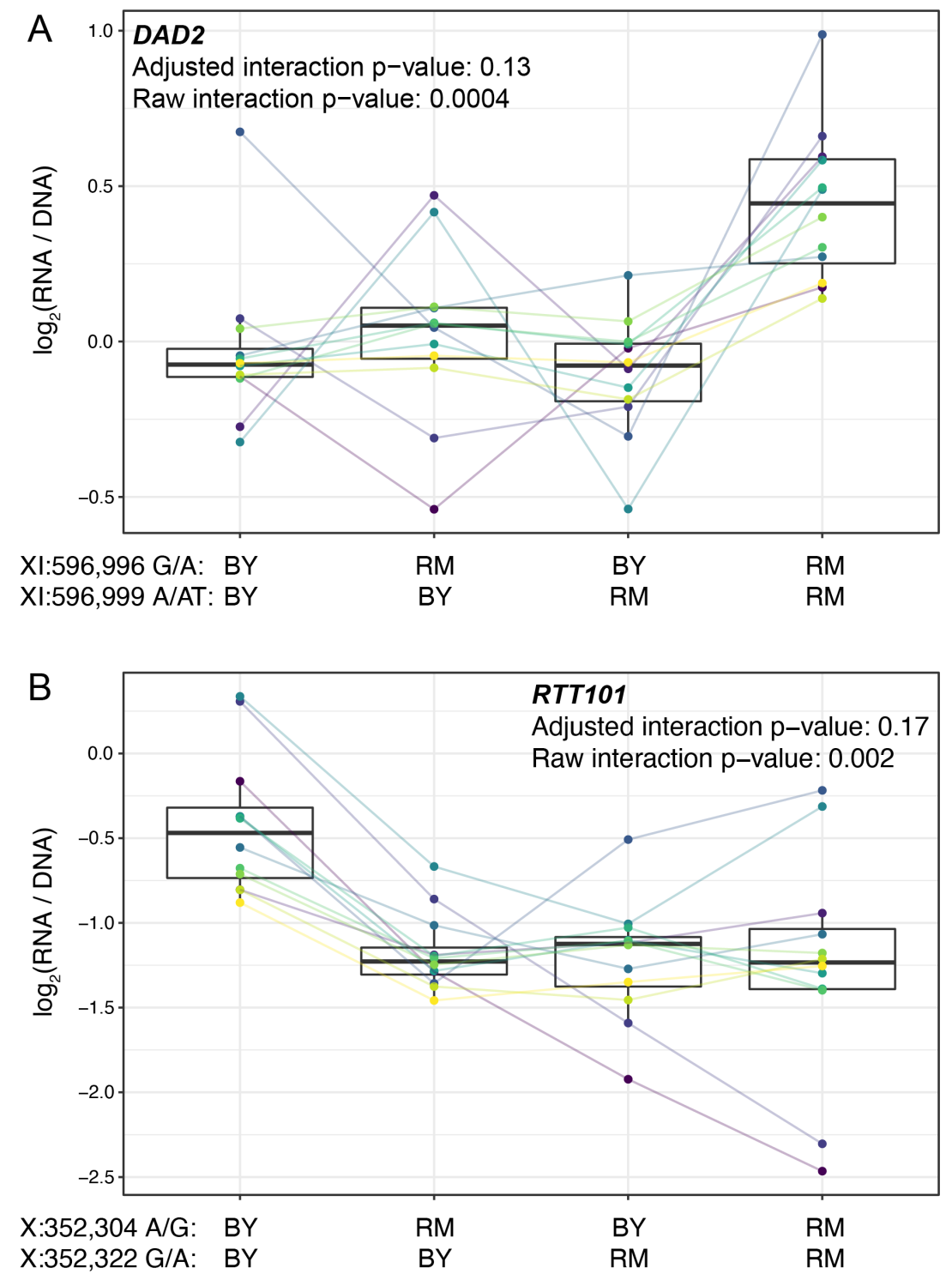

Figure 4: Epistasis among promoter variants. Each panel shows, for one gene, MPRA expression driven by four oligos with the indicated combination of BY and RM alleles at the two variants. Each panel states the gene name in bold along with multiple-testing adjusted and raw interaction p-values. Variants are given as "chromosome:position reference/alternative allele". Colored lines between boxplots connect the data for a given oligo in the different biological replicates. Boxplots show the median as thick line, with the box showing the $25^{\text {th }}$ and $75^{\text {th }}$ percentiles. Whiskers show the largest value no further than 1.5 times the inter-quartile range; any observations beyond this range are shown as individual points. A). Promoter variants for DAD2. B) Promoter variants for RTT101. 


\section{Characteristics of causal variants}

The identification of hundreds of causal variants enabled us to ask whether causal variants tend to share molecular or population genetic characteristics. To address this question, we assembled a set of 2,998 features describing each variant. These features comprised sequence characteristics of the alleles, evolutionary properties of the variant, and features that describe the gene that is regulated by the promoter in which the variant resides (Table S8 \& Supplementary File S1). Most features $(2,967)$ described transcription factor (TF) binding (see below).

We divided variants into a "causal" group (defined as variants with an FDR of $\leq 5 \% ; n=459$ ) and a non-causal group (variants with a raw $p$-value $>0.2 ; n=3,774$ ). For variants located in divergent promoters that were assayed in both orientations, the results from the two orientations were considered separately. For this reason, the number of causal variants in these analyses was slightly higher than the 451 unique variants reported above. We used logistic regression to test the association of each feature with variant causality (Table S9).

Overall, causal variants were more likely to be SNVs than indels (Figure 5A). At the same time, longer indels were more likely to be causal than shorter indels (Figure 5A). Causal variants were less likely to be bound by a nucleosome in the genome $(\mathrm{FDR}=4 \%)$. Nucleosomes may shield such variants from DNA-binding factors even on the plasmid reporter if the local DNA sequence around the tested variants can direct nucleosome formation at least partially.

Causal variants were enriched at nucleotides with higher PhastCons scores (FDR $=1 \%$, Figure $5 \mathrm{~A})$, suggesting that natural variants that occur at nucleotides that are more conserved across yeast species are more likely to affect gene expression than those at less conserved nucleotides. Variants in the promoters of essential genes were less likely to be causal (FDR $=6 \%$ ). Causal variants were also less likely to occur in promoters of genes with many synthetic genetic interactions (Figure 5A), which tends to be a property of essential genes (Costanzo et al., 2016). Essential genes are required for yeast viability, and are known to have less genetic (Albert et al., 2018), environmental (Eng et al., 2010), and stochastic (Newman et al., 2006) variation in gene expression. The observation that natural variants in promoters of essential genes are less likely to perturb gene expression is consistent with negative selection acting to purge causal variants from essential gene promoters. In further support of this hypothesis, causal variants had lower derived allele frequencies than non-causal variants $(\mathrm{FDR}=10 \%)$, as expected if negative selection prevents variants that affect gene expression from rising to higher frequency (Kita et al., 2017; Ronald and Akey, 2007). 


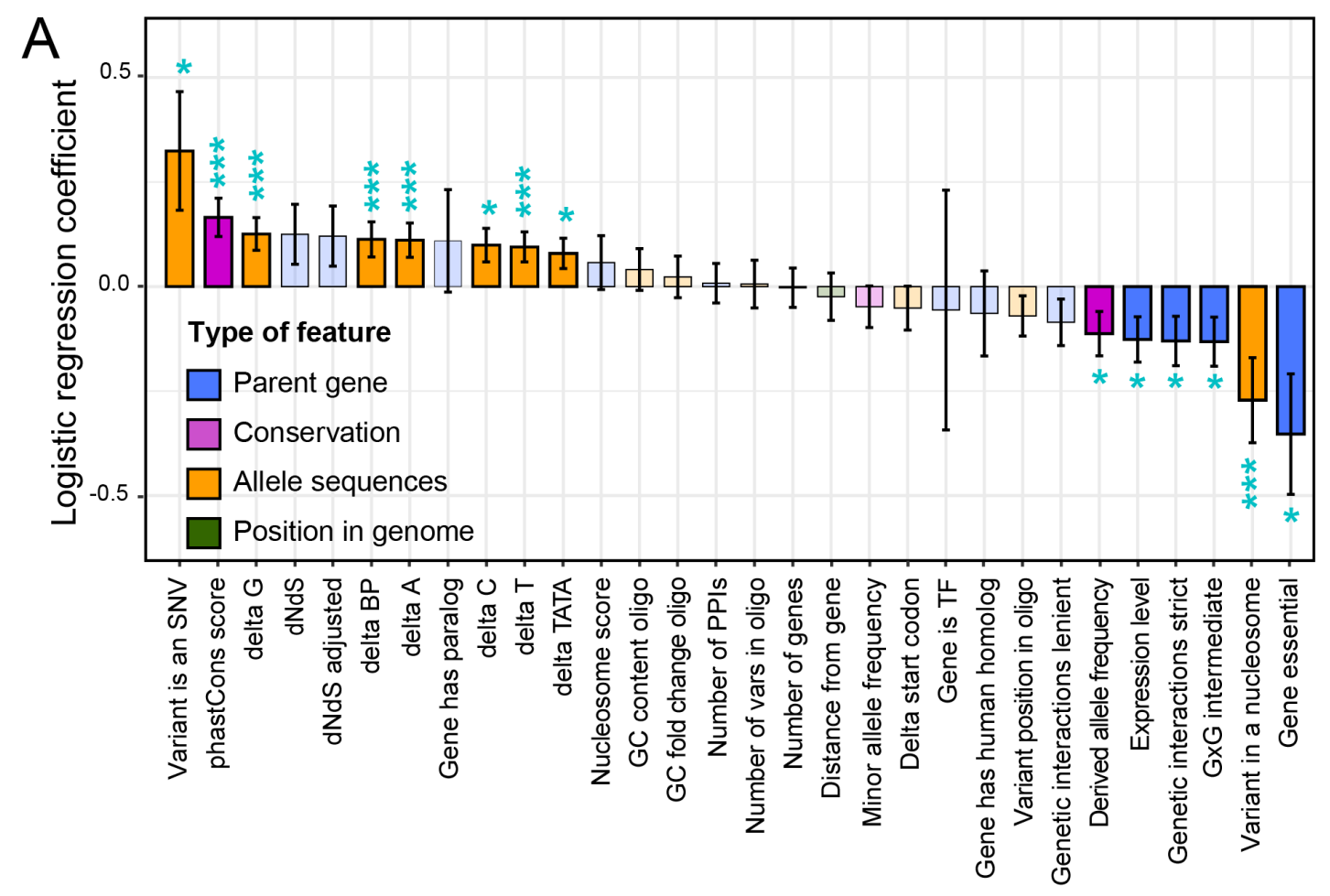

$\mathrm{B}$
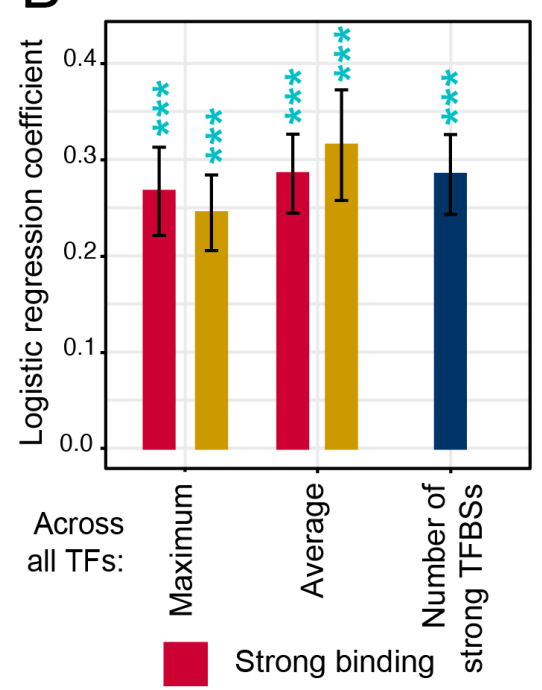

Minus strand

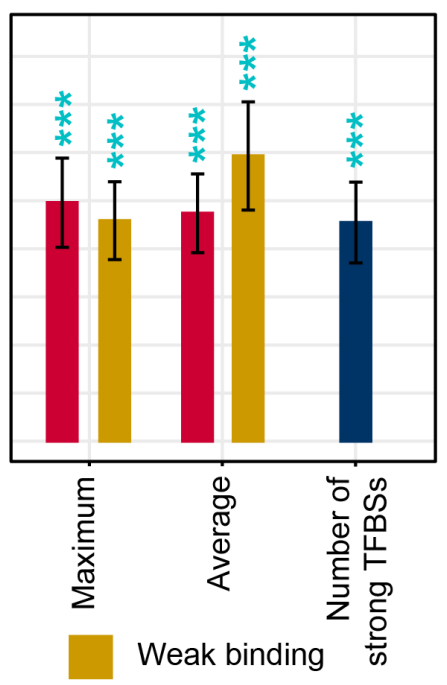

C

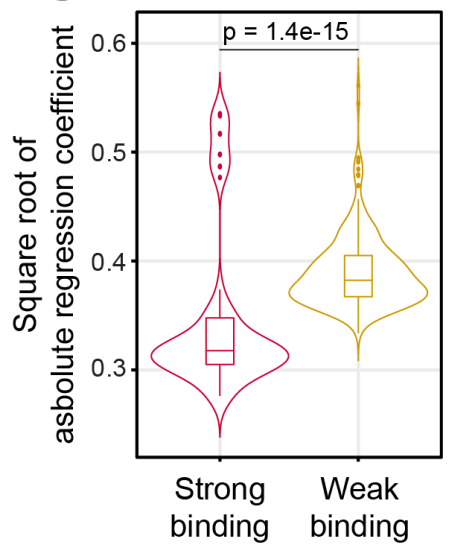

Figure 5: Association of features with variant causality. A) Non-TF features. The figure shows the strength of association between each feature and variant causality. Error bars show the standard error of the mean. Significant associations are indicated by three stars (FDR $<5 \%$ ) or one star (nominal p-value $<0.05$ ). Non-significant features are shown in lighter coloring. B) TF summary features aggregated across all 196 TFs, separated by strand, mode of aggregation across TFs, strength of binding (weak or strong), and mode of comparing allelic PWM scores across sliding sequence windows spanning each variant (Methods). Each of these summary features was significantly associated with variant causality at an FDR of $<5 \%$. C) Distributions of logistic regression estimates for strong vs. weak binding for individual TFs. The $\mathrm{p}$-value shows the result of a Wilcoxon rank test. 


\section{Causal variants alter predicted transcription factor binding}

Gene expression is shaped by chromatin state as well as by the binding of TFs to cis-regulatory elements (Rando and Winston, 2012). Previous work suggested that while cis-eQTLs can perturb multiple aspects of chromatin, these molecular changes tend to ultimately be caused by sequence-directed differences in TF binding (Degner et al., 2012; Kasowski et al., 2013; Kilpinen et al., 2013; McVicker et al., 2013). To explore the influence of single causal variants on TF binding, we computed the expected propensity of each of 196 TFs to bind to the two alleles at each variant. Because some TFs have different affinities for the two DNA strands at their binding sites (de Boer et al., 2020), we separately considered binding to the sense and the antisense strand, as well as in a strand-agnostic manner. TFs bind to individual "strong" sites that closely match their motif, as well as to weaker sites with imperfect motif matches (de Boer et al., 2020). To capture this distinction, we computed separate feature sets that considered only strong or only weak binding sites. Finally, we also aggregated the 196 TF-specific feature sets into summary features that reported maximum and average allelic differences at each variant across the 196 TFs (Methods).

Overall, TF binding was strongly and broadly associated with variant causality (Figure 5B). Across the 2,940 TF-specific features, 481 features for 139 distinct TFs showed significant associations at an FDR of 5\% (Table S9). All of the 27 summary features were significant at this threshold. For example, causal variants were more likely to result in gains or losses of strong binding sites $(62 \% ; n=286)$ than non-causal variants $(49 \% ; n=1,846 ;$ FET $p=6 e-8)$. These associations were found on both DNA strands (Figure 5B).

Causality was associated with differences in strong as well as weak TF binding (Figure 5B). While yeast promoters harbor relatively few strong binding sites, they contain many binding sites that are individually weak but that in combination greatly influence promoter activity (de Boer et al., 2020). In our logistic regression analyses of the 196 individual TFs, differences in the various weak TF binding metrics showed stronger associations with causality than those in the strong TF binding metrics (Figure 5C). Because of the relatively low density of strong binding sites, many natural variants change no or only a small number of these sites. In contrast, the high density of weak binding sites presents a large mutational target, such that essentially every variant perturbs one or more weak binding sites. Evidently, these subtle differences can result in detectable expression changes. Overall, these analyses provided clear evidence that causal variants often perturb TF binding.

\section{Prediction of causal variants}

The prediction of the effects of individual variants in a given genome is a major challenge for modern genetics and genomics. We tested whether the hundreds of causal variants we identified might enable us to predict the effects of individual cis-acting variants from their annotated features. We built 112 multiple logistic regression models for predicting variant causality from various feature subsets (Table S10). We trained these models using repeated 10-fold crossvalidation on a random subset comprising $90 \%$ of the causal and non-causal variants and tested model performance on the remaining $10 \%$ of the variants. The best model achieved an area under the receiver operating curve (AUC) of 0.71 (Figure 6A). 

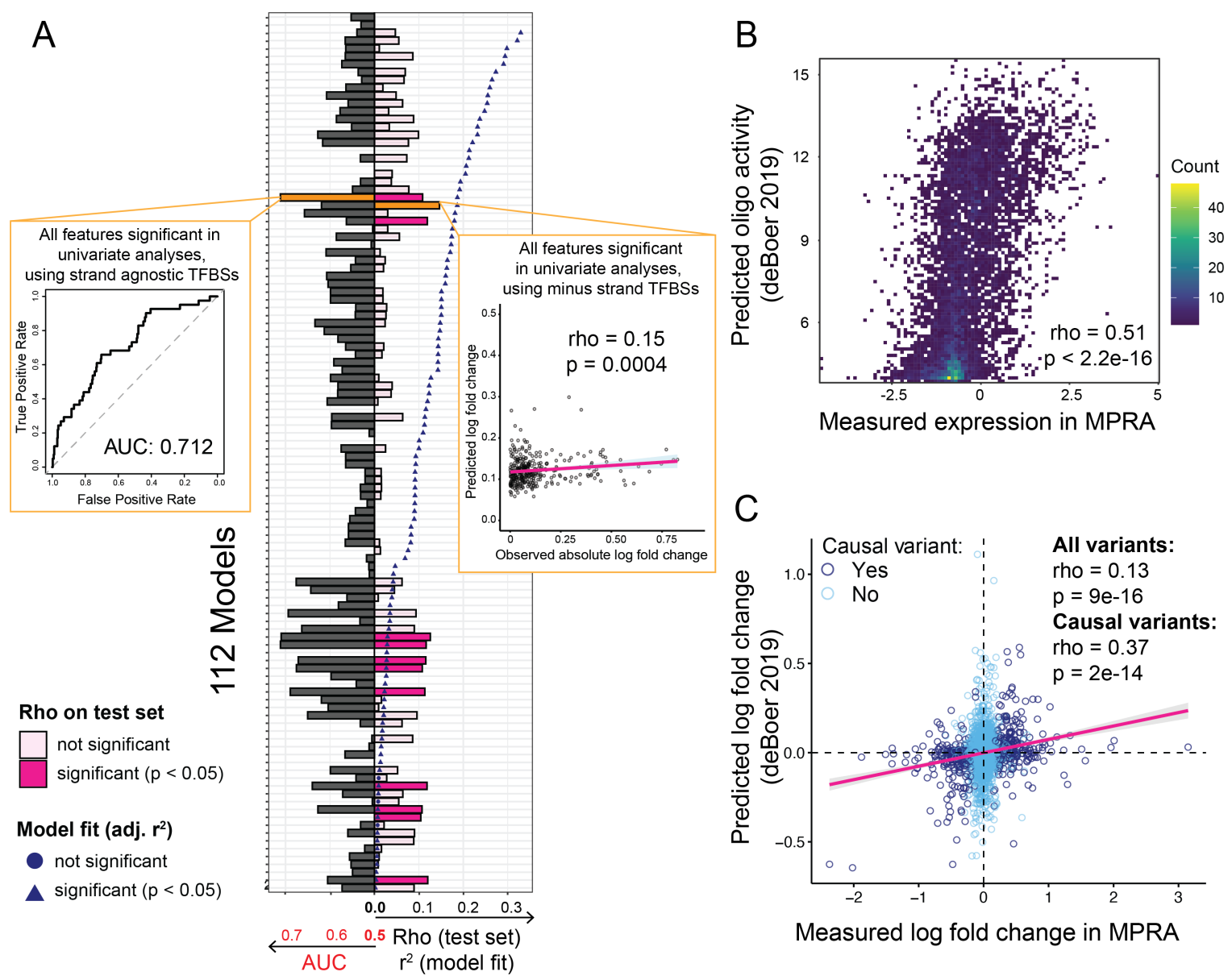

Figure 6: Prediction of causal variants and variant effects. (A) Prediction results for 112 models. On the left, the plot shows the performance of binomial classifiers on the $10 \%$ test as black bars. On the right, the plot shows the performance of the linear predictors of variant effects as spearman correlation coefficients (rho) between actual and predicted log fold-changes in expression as pink bars. Blue symbols show $\mathrm{r}^{2}$ values for each model when fit to the entire dataset. The best classifier and linear model are indicated by orange bars and shown as insets. (B) Measured expression driven by each oligo versus expression predicted by the deBoer model. (C) Observed fold-changes of individual variants measured in our MPRA versus fold-changes predicted by the deBoer model. The pink line is the linear regression for all variants.

We also built a series of multiple linear regression models that used the same 112 feature combinations to predict the absolute log fold-change caused by a given variant. When fit to the entire dataset, nearly all models fit the data better than expected by chance, with $\mathrm{r}^{2}$ values of up to 0.33 at a p-value of 3e-50 for a model including non-TF features as well as all TF features (Figure 6A). A model considering only the TF features fit the data almost as well $\left(\mathrm{r}^{2}=0.32, \mathrm{p}=\right.$ 7e-49). The median $\mathrm{r}^{2}$ across the 112 models was 0.09 . Next, we used $90 \%$ of the variants to train these linear regression models using repeated 10 -fold cross-validation and predicted absolute log fold-change in the remaining $10 \%$ of the variants. The best correlation between predicted and observed fold-changes was rho $=0.15(\mathrm{p}=0.0004)$. Several other models performed nearly as well (Figure 6A). The median model prediction performance was rho $=$ 0.07 . We retrained the 112 models with cross-validated elastic-net regularization, which is less 
prone to potential overfitting. The best $(\mathrm{rho}=0.12, \mathrm{p}=0.02)$ and median $(\mathrm{rho}=0.005)$ regularized models performed no better than the respective unregularized linear models. Overall, prediction models built from various feature sets were able to predict the identity and effect size of causal variants better than chance, but with modest accuracy.

Recently, deBoer et al. reported a model for predicting reporter gene expression driven by millions of random DNA fragments (de Boer et al., 2020). We tested whether this model was capable of predicting individual variant effects in our data. Using the DNA sequence centered on each variant in our library as input, we predicted reporter gene expression driven by each oligo in our libraries. These predicted expression values showed a significant correlation with measured expression in our MPRA (Figure 6B). We then computed the predicted fold change of each variant as the difference between the predicted expression for the respective BY and RM oligos. The predicted and measured fold-changes of all variants correlated significantly (Figure 6C). This correlation increased for variants that were causal in our data (Figure 6C), although this subset would be unknown during variant effect prediction from genome sequence alone. When we ignored the direction of the fold-changes, prediction performance was reduced for all variants (rho $=0.09, p=1 \mathrm{e}-8)$, and degraded completely for causal variants (rho $=0, p=0.9$ ). This suggests that much of the ability of this independent model to predict variant effects in our data derives from the model's ability to correctly capture whether altered binding of individual transcription factors to a given allele increases or decreases expression.

In summary, models based on individual features trained on our variant effects, as well as a completely independent model (de Boer et al., 2020), showed similar ability to predict variant effects from DNA sequence. Although prediction performance was modest in both cases, the fact that a model trained on an independent experiment can capture some effects in our data demonstrates that the prediction of individual variant effects from DNA sequence alone is becoming possible. 


\section{Discussion}

In this work, we used an MPRA to examine the effects of roughly half of all intergenic DNA sequence variants between two yeast strains and identified hundreds of variants with significant, cis-acting effects on gene expression. These significant variants reflected the effects of known local eQTLs, suggesting that we have identified causal variants that underlie natural regulatory variation. Several insights emerged from in-depth analysis of these causal variants.

First, the molecular basis of local eQTLs can include single (as for $O L E 1$ ) or multiple (as for $C W P 1$ ) causal variants. Studies seeking to identify the molecular basis of QTL regions often implicitly assume that each QTL is driven by a single causal variant. However, efforts to finemap QTLs for organismal traits often find that multiple, linked causal variants exist in a region (Kroymann and Mitchell-Olds, 2005; Sinha et al., 2008; Steinmetz et al., 2002). Whether multiple variants also underlie QTLs for molecular traits such as gene expression was less clear, especially for local eQTLs in yeast, given the small mutational target size of the compact regulatory regions. Our results show that the molecular basis of local regulatory variation can involve multiple causal variants even in a single pair of yeast strains.

In some promoter regions (as for UFO1), we detected variants with effects in opposing directions that cancelled each other out, resulting in no local eQTL signal, demonstrating that QTL mapping can miss linked causal variants of opposite effect. Similarly, recent work has shown that the number of trans-acting loci affecting gene expression throughout the genome may have been greatly underestimated due to linkage in experimental crosses with limited recombination (Metzger and Wittkopp, 2019). These results paint an emerging picture of a highly polygenic architecture of gene expression variation, with dozens of trans-acting loci across the genome (Albert et al., 2014b, 2018; Brion et al., 2020; Metzger and Wittkopp, 2019), each of which may harbor multiple causal variants.

Second, we detected several instances of non-additive epistatic interactions between variants in the same promoter. Previous work revealed epistatic eQTL pairs that influence the expression of a given gene, including between cis and trans eQTLs as well as between trans eQTLs (Albert et al., 2018; Brem et al., 2005). Very few of these cases have been resolved to individual variants (Brem et al., 2005; Lutz et al., 2019). Our results show that there can also be epistasis between multiple causal variants within a single local eQTL. Nevertheless, most of our assayed variant pairs act additively. Even for pairs with the most significant epistasis, the quantitative departures from additivity tended to be small (Figure $4 \& \mathrm{~S} 10$ ). This result is consistent with searches for epistatic QTLs for various growth traits in this cross. Although examples of higher-order epistatic interactions with profound effects on some traits have been reported (Forsberg et al., 2017), most of the hundreds of detected epistatic pairs involve small deviations from additivity that account for minuscule fractions of phenotypic variance (Albert et al., 2018; Bloom et al., 2015), as expected from quantitative genetic theory (Hill et al., 2008).

Third, cis-acting variants showed signals of evolving under negative selection, in that the derived alleles of causal variants tended to have reduced population frequencies and were less likely to be found in the promoters of essential genes. Similar results (reviewed in (Signor and Nuzhdin, 2018)) have been reported in yeast (Kita et al., 2017; Ronald and Akey, 2007), plants (Josephs et al., 2015) and humans (Battle et al., 2014), but were based on studies in crosses subject to linkage among neighboring variants, or in natural populations subject to both linkage disequilibrium and differences in statistical power for variants with different population 
frequencies. Our MPRA results are free from confounding effects of linkage and population frequency and extend the observation of negative selection to single, causal cis-acting variants.

Fourth, causal variants were enriched for sequence changes that altered predicted transcription factor binding. This enrichment was present for strong binding sites, as well as weak sites that do not pass strict binding site detection thresholds. Emerging evidence suggests that in addition to strong, high-affinity binding sites, intergenic DNA harbors an abundance of weak, low-affinity binding sites with imperfect motif matches (de Boer et al., 2020; Tanay, 2006; Wunderlich and Mirny, 2009). This latter group provides a larger mutational target than the few strong exact motif matches. As a consequence, almost every natural variant perturbs one or multiple weak binding sites. The joint effects of perturbations to weak sites could further contribute to molecular architectures in which several causal variants shape the overall activity of a given promoter in a given individual. Alterations to weak binding sites may also help explain why many inferred causal variants in human diseases are located close to, but do not obviously change, recognizable TF motifs (Farh et al., 2015).

Our approach had several limitations. First, not all potential cis-acting variants were assayed in our libraries, including roughly half of intergenic variants as well as variants in gene regions such as the most proximal bases of the core promoter, the gene body, the 3'UTR, and the terminator. Future work with dedicated libraries to study these variants will likely reveal many additional causal effects. Meanwhile, the concordance of our results with local eQTLs suggests that we have discovered a non-trivial fraction of causal variants, and that, by extension, many cis-acting variants do indeed reside in promoter regions. Second, causal variants typically have small effects on gene expression, necessitating replicate assays to ensure high statistical power. Higher levels of replication, as well as further optimization of assay design, are likely to improve variant detection and effect quantification. Finally, our plasmid-bound assay cannot capture the full chromatin state of variants in the genome. Nevertheless, our causal variants correlated with local eQTL effects measured in the native genomic context, showing that chromatin state does not override the effects of all variants. This agreement was stronger for variants that reside in nucleosome-free regions than for nucleosome-bound variants. If nucleosomes do not form on the plasmids, such regulatory variants may be exposed to a regulatory environment similar to that in the genome. More broadly, the precise chromatin context in which a variant is embedded likely influences its exact effect on gene expression, consistent with the considerable differences revealed by MPRAs inserted at different sites in the human genome (Maricque et al., 2019), as well as with the high degree of tissue-specificity of human cis-eQTLs (GTEx Consortium et al., 2017).

The prediction of the consequences of individual DNA variants is a major area of research, especially given that accurate predictions could aid discovery of disease-causing mechanisms and diagnosis of individual patients with unknown genetic disorders. As a consequence, a plethora of computational methods aiming to predict the severity or molecular consequences of individual variants has been developed (for example, (Huang et al., 2017; Kircher et al., 2014; Lee et al., 2015; Zhou et al., 2018; Zhou and Troyanskaya, 2015), reviewed in (Nishizaki and Boyle, 2017)). Although our models integrating various features to predict the identity and effect size of causal variants performed better than chance, no single feature and no simple combination of features achieved high prediction accuracy. While the size of our dataset, which included several hundred causal variants, may be insufficient to train predictors with better performance, an independent model trained on millions of DNA sequences (de Boer et al., 2020) 
and applied to our data performed similarly. Our prediction accuracies are also comparable to those obtained from state-of-the-art machine-learning tools applied to human MPRA data (Kircher et al., 2019) and to simulated genetic architectures (Liu et al., 2019). Clearly, prediction of variant effects remains a challenging problem even in comparatively simple yeast promoters. Models trained in a range of environmental conditions, which would provide variation in chromatin contexts, as well as on MPRA data with longer and more diverse flanking sequences (Kircher et al., 2019) may further improve predictive accuracy. 


\section{Methods}

MPRA design and analysis code is available at

https://github.com/frankwalbert/promoterVariants. Unless otherwise specified, analyses were performed in R (https://www.r-project.org ), using various packages from the tidyverse (https://tidyverse.tidyverse.org/index.html) (Wickham et al., 2019) and Bioconductor (https://www.bioconductor.org) (Huber et al., 2015). Specific packages are listed below. Sequences of primer and elements of the reporter construct are available in Table S11.

\section{MPRA library design}

Our design was based on 45,543 variants previously detected from short-read sequencing data of the BY and RM strains (Bloom et al., 2013). Because the BY strain is nearly identical to the genome reference strain (Engel et al., 2014), RM alleles are by definition "alternative" alleles. Variants close to the telomeres were excluded as described in (Albert et al., 2014a). Variants included SNVs and short indels (Supplementary File S2). When multiple alternative alleles were reported for a variant, we used the alternative allele with the highest likelihood. We obtained gene annotations for the sacCer3 yeast reference genome build from SGD

(https://www.yeastgenome.org) (Cherry et al., 2012). Coding genes, as well as tRNAs, snoRNAs, snRNAs, and other non-coding RNAs were included in the design. Noncoding genes that overlapped a coding gene were removed, along with genes on the mitochondrial and $2 \mu$ plasmid genomes.

We defined transcription start sites based on full-length yeast transcript isoforms obtained by capturing and sequencing both the 5' cap and 3' polyadenylation site of yeast RNAs (Pelechano et al., 2013). Specifically, we considered transcript isoforms reported in Supplementary Data S2 from (Pelechano et al., 2013) that completely contained their annotated gene, avoiding isoforms that initiated transcription inside of annotated gene models or that terminated transcription prematurely. For each gene, we summed the number of reported counts for all isoforms that started at the same 5' base in YPD medium. Based on these summed counts, we selected the 5' position with the most read counts to represent the transcription start site for the given gene.

For the TSS library, we included DNA variants between BY and RM located within the $144 \mathrm{bp}$ upstream of the transcription start site for each gene. We designed "oligo blocks", sets of oligos carrying allelic versions of these $144 \mathrm{bp}$ sequences. We extracted the reference genome sequence for these regions to form oligos carrying BY alleles at all variants. For each variant in the $144 \mathrm{bp}$, we created one additional oligo carrying the RM allele at this variant. We also generated one oligo per block that carried RM alleles at all variants. The TSS library comprised such oligo blocks for all genes that harbored variants in the design space of this library.

For the Upstream library, we considered all variants located between 72 bp upstream of the start codon of each gene and the coding sequence of the next upstream gene, up to a maximum distance of $1 \mathrm{~kb}$. For each such variant, we created an oligo block consisting of one oligo that carried the reference genome sequence centered on the variant and one oligo that carried the same sequence but with the RM allele at the variant. We subsampled 4,547 variants from this design. Specifically, we included all variants located in promoters whose genes had at least some evidence (nominal $\mathrm{p}<0.05$ ) of allele-specific expression (ASE) in either of two ASE datasets (Albert et al., 2018, 2014a). We also included variants from 1,000 randomly selected genes 
without evidence of ASE ( $p>0.2)$, as well as 2,062 additional variants selected at random from the remaining variants.

Both designs were strand-specific, such that for genes located on the plus strand we designed oligos based on the reference genome sequence, while for genes located on the minus strand, we used the reverse-complement of the reference sequence. Thus, in the finished reporter constructs, all oligos were correctly oriented with respect to the fluorescent reporter gene.

We removed oligo blocks in which at least one oligo happened to contain a restriction site that would be recognized by the restriction enzymes we used during cloning. We also removed oligo blocks in which RM insertion variants increased the length of at least one oligo to more than the synthesis limit of $200 \mathrm{bp}$.

In both libraries, we included an identical set of 200 oligos based on promoter fragments studied by Sharon et al. (Sharon et al., 2012). Because the promoter fragments in that study were shorter (103 bp) than ours (144 bp), we added a random DNA sequence

(TATAGAACGGAATCACCTCTGACAAGTAGCGTCAAATCGGT) between the AscI cloning site and the $\mathrm{p} 2$ priming site such that this random sequence was removed during cloning (Figure S3). This extra sequence safeguarded against preferential PCR amplification of what would otherwise have been shorter oligo molecules.

To each designed oligo sequence, we added restriction sites and library-specific priming sites as shown in Figure S3. The resulting oligos had a median length of 195 bp. RM insertion variants increased the length of some oligos, such that the maximum oligo length was $200 \mathrm{bp}$. Because oligo synthesis is challenging for sequences rich in adenine (which are enriched in promoter sequences), we reverse-complemented the designed sequences of oligos that carried more adenines than thymines. Because the single-stranded oligo libraries are amplified by PCR prior to use, these reverse complement oligos behaved equivalently equivalent to the designed oligos in downstream experiments. Oligos were purchased as one pool from Agilent Technologies.

\section{Reporter design}

Inspired by the design of prior work (Sharon et al., 2012), we placed the promoter fragment library upstream of a fluorescent yEGFP gene on a plasmid (Figure S3). Similar to Kosuri et al. (Kosuri et al., 2013), we measured reporter gene expression by quantifying yEGFP mRNA instead of fluorescence signal. Plasmids carried a CEN/ARS origin of replication and an $A D H 1$ terminator downstream of the reporter constructs. We included random $20 \mathrm{bp}$ barcodes downstream of the yEGFP gene, such that the barcodes were transcribed as part of the yEGFP mRNA. Prior to insertion of the yEGFP gene into plasmids, we used paired-end sequencing to generate a dictionary linking each random barcode to the promoter fragment it tagged. We amplified the barcode from plasmid DNA or yEGFP cDNA to generate Illumina sequencing libraries. Reporter expression was quantified by high-throughput sequencing and counting of barcode reads. Details on these procedures are given below.

For the TSS library, the designed promoter fragments were inserted immediately upstream of the yEGFP ORF. For the Upstream library, an invariant HIS3 minimal promoter was inserted between the oligo sequences and the yEGFP ORF (Sharon et al., 2012). 


\section{Initial library amplification and barcoding}

The TSS and Upstream libraries were selectively amplified from the common oligo pool (Agilent). Per library, each of eight parallel reactions contained $0.2 \mu \mathrm{L}$ of oligo pool diluted 1:10 in TE buffer for $\sim 10 \mathrm{ng}$ template DNA, $5 \mu \mathrm{L}$ of $2 \mathrm{x}$ Kapa library amplification mix (Roche, KK2702), $0.2 \mu \mathrm{L}$ forward primer $(10 \mu \mathrm{M}$; TSS: orc281, Upstream: orc 279), $0.2 \mu \mathrm{L}$ reverse primer $(10 \mu \mathrm{M}$; TSS: orc285; Upstream: orc283), and $4.4 \mu \mathrm{L}$ water. Cycling conditions were: $98^{\circ} \mathrm{C}$ for $2 \mathrm{~min}, 5$ cycles of $98^{\circ} \mathrm{C}$ for $3 \mathrm{~s}, 50^{\circ} \mathrm{C}$ for $20 \mathrm{~s}, 60^{\circ} \mathrm{C}$ for $10 \mathrm{~s}, 10$ cycles of $98^{\circ} \mathrm{C}$ for $3 \mathrm{~s}$, $60^{\circ} \mathrm{C}$ for $30 \mathrm{~s}$, and a final extension at $60^{\circ} \mathrm{C}$ for $2 \mathrm{~min}$ followed by a hold at $10^{\circ} \mathrm{C}$. The eight parallel reactions were pooled, cleaned up using QiaQuick PCR purification kits (Qiagen \#28106), eluted in $30 \mu \mathrm{L}$ EB buffer, and quantified with Qubit HS DNA kits (Thermo Fisher \#Q32854).

To generate barcoded libraries, we performed PCR in 8 parallel reactions. Each contained $10 \mathrm{ng}$ of amplified library, $10 \mu \mathrm{L} 5 \mathrm{x}$ Phusion buffer, $1 \mu \mathrm{L}$ dNTP mix (10mM, Invitrogen \#18427013), $1 \mu \mathrm{L}$ forward primer $(10 \mu \mathrm{M}$; TSS: orc291, Upstream: orc 287$), 1 \mu \mathrm{L}$ reverse primer $(10 \mu \mathrm{M}$; TSS: orc292, Upstream: orc288), $0.5 \mu$ L Phusion HS II DNA Polymerase (ThermoFisher \#F549L), and water to $50 \mu \mathrm{L}$. Cycling was performed as follows: $98^{\circ} \mathrm{C}$ for $2 \mathrm{~min}, 14$ cycles (TSS) or 12 cycles (Upstream) of $98^{\circ} \mathrm{C}$ for $3 \mathrm{~s}, 60^{\circ} \mathrm{C}$ for $30 \mathrm{~s}, 72^{\circ} \mathrm{C}$ for $30 \mathrm{~s}$, a final extension at $72^{\circ} \mathrm{C}$ for $2 \mathrm{~min}$, and a hold at $10^{\circ} \mathrm{C}$. The eight parallel reactions per library were combined, cleaned up using QiaQuick PCR purification kits, eluted in $30 \mu \mathrm{L}$ EB buffer, and quantified with Qubit HS DNA kits.

Because the barcodes are part of the reporter mRNA molecules, their sequence potentially influences mRNA abundance in cis, for example by affecting mRNA stability. Indeed, pilot experiments suggested that barcodes with a high number of guanines had lower expression, in line with known effects of guanines in the 3'UTR (Shalem et al., 2015). Barcodes starting with two guanines had particularly low expression, and an adenine at the first position increased expression variance. To increase overall library expression while maintaining high barcode complexity, all experiments reported here used random barcodes in which 1) the first base was either cytosine or thymine, 2) the next three positions and every remaining even position contained no guanines but each of the other three DNA bases at equal frequency, and 3) the remaining odd positions carried each of the four bases at equal frequency.

\section{Plasmid library generation}

The base plasmid "RCP83" was generated synthetically (Gen9/Ginkgo Bioworks) with a bacterial ampicillin marker and a yeast kanMX resistance cassette (Supplementary File S3). The barcoded library was directionally ligated into the plasmid at an SfiI site. Upstream of this site, the plasmid contained the "PS1" priming site used in barcode annotation (see below).

Downstream of the SfiI site, the plasmid carried an $A D H 1$ terminator, ensuring efficient termination of the reporter constructs. We isolated RCP83 from E. coli cultures by maxi-prep using Qiagen Plasmid Plus Purification kits (Qiagen \#12963,\#12965) and quantified plasmid DNA using Qubit dsDNA HS Assay Kit (Thermo Fisher \#Q32854). We digested $10 \mu \mathrm{g}$ of RCP83 using $10 \mu \mathrm{L}$ SfiI enzyme (NEB, \#R0123S) in $50 \mu \mathrm{L}$ 10x NEB CutSmart buffer and water to $500 \mu \mathrm{L}$. This mixture was incubated at $50^{\circ} \mathrm{C}$ for $4 \mathrm{~h}$ and cooled to room temperature. To prevent religation of the backbone, we added $10 \mu \mathrm{L}$ of Shrimp Alkaline Phosphatase (NEB $\# \mathrm{M} 0371 \mathrm{~L}$ ) and incubated at $37^{\circ} \mathrm{C}$ for $1 \mathrm{~h}$. We purified the digested vector from a $0.8 \%$ agarose 
gel (1.2 g agarose Fisher \#21-255-00GM) in $150 \mathrm{~mL}$ 1x TAE (Fisher \#FERB49)) using a QiaQuick Gel Extraction Kit (Qiagen \#28706) and quantified using a Qubit dsDNA HS Assay Kit.

We digested $1 \mu \mathrm{g}$ of barcoded library using $5 \mu \mathrm{L}$ SfiI enzyme, $10 \mu \mathrm{L}$ 10x NEB CutSmart buffer, and water to $100 \mu \mathrm{L}$ at $50^{\circ} \mathrm{C}$ for $2 \mathrm{~h}$. Digested insert was purified using QiaQuick PCR purification and eluted in $30 \mu \mathrm{EB}$.

Ligation of the digested library into the digested backbone was performed by mixing $1 \mu \mathrm{g}$ of vector, $100 \mathrm{ng}$ of library, $80 \mu \mathrm{L}$ of 10x T4 DNA ligase buffer, $4 \mu \mathrm{L}$ of T4 DNA ligase (NEB $\# \mathrm{M} 0202 \mathrm{M})$, and water to $800 \mu \mathrm{L}$. The mixture was incubated at $16^{\circ} \mathrm{C}$ for $18 \mathrm{~h}, 65^{\circ} \mathrm{C}$ for $20 \mathrm{~min}$, and held at $12^{\circ} \mathrm{C}$. The reaction was cleaned up with a DNA Clean and Concentrator kit (Zymo Research, \#D4013) and eluted in $25 \mu \mathrm{L}$ water.

Transformation into E. coli was performed by electroporation into E. cloni 10G SUPREME Electrocompetent Cells (Lucigen, \#60080-2), in 11 parallel transformations (1 mL each) on a Bio-Rad MicroPulser (Bio-Rad, \#165-2100). The parallel transformations were combined and mixed with a total of $9.5 \mathrm{~mL}$ of recovery medium. To estimate the number of transformants obtained, we plated a dilution series (10-fold dilution steps from 1:100 to $1: 10^{6}$ ) on LB carbenicillin $(100 \mu \mathrm{g} / \mathrm{mL})$ plates, grew the plates overnight at $30^{\circ} \mathrm{C}$ and counted colonies after $24 \mathrm{~h}$. We obtained an approximate of 25 million and 230 million transformants for the TSS and Upstream libraries, respectively. Negative controls, for which we had performed the ligation and transformation with digested backbone but no insert, yielded negligible numbers of colonies. The transformed cells were plated on $15 \mathrm{~cm} \mathrm{LB}+$ carbenicillin plates $(500 \mu \mathrm{L}$ per plate), grown overnight at $30^{\circ} \mathrm{C}$, and scraped into a total of $25 \mathrm{~mL} \mathrm{LB}$ medium. The optical density $\left(\mathrm{OD}_{600}\right)$ of these cells suspensions was determined, and $2 \mathrm{OD}_{600}$ units $(\sim 1$ billion cells) were grown overnight at $30^{\circ} \mathrm{C}$ in $400 \mathrm{~mL} \mathrm{LB}+$ carbenicillin. After $24 \mathrm{~h}$, plasmids were isolated from $200 \mathrm{~mL}$ of these cultures using Qiagen Plasmid Plus Purification kits (Qiagen \#12963, \#12965). The remaining $200 \mathrm{~mL}$ of the overnight cultures were spun down, resuspended in $6 \mathrm{~mL} \mathrm{20 \%}$ glycerol, and frozen at $-80^{\circ} \mathrm{C}$ in $1 \mathrm{~mL}$ ultra-concentrated aliquots.

\section{Barcode annotation}

We annotated designed promoters to random barcodes by high-throughput sequencing. To generate the sequencing libraries, we performed four parallel PCR reactions each for the TSS and the Upstream library. In each reaction, we combined $800 \mathrm{ng}$ of plasmid library with $25 \mu \mathrm{L}$ 2x Kapa library amplification mix (Roche, \#KK2702), $1 \mu \mathrm{L}$ forward primer (10 $\mu \mathrm{M}$; orc 295), 1 $\mu \mathrm{L}$ reverse primer $(10 \mu \mathrm{M}$; orc 296$)$, and water to $50 \mu \mathrm{L}$. PCR was performed as follows: $98^{\circ} \mathrm{C}$ for $2 \mathrm{~min}, 10$ cycles of $98^{\circ} \mathrm{C}$ for $3 \mathrm{~s}, 72^{\circ} \mathrm{C}$ for $30 \mathrm{~s}$, and a final extension at $72^{\circ} \mathrm{C}$ for 2 min with a hold at $12^{\circ} \mathrm{C}$. The four reactions were combined, and clean-up performed using $360 \mu \mathrm{L}$ AmPure $\mathrm{XP}$ beads for $200 \mu \mathrm{L}$ combined reactions. Beads were incubated with the library at room temperature for $5 \mathrm{~min}$, separated on a magnetic rack, washed twice with $500 \mu \mathrm{L} 80 \% \mathrm{EtOH}$, and eluted from the beads with $50 \mu \mathrm{L}$ elution (TE) buffer for 5 min. Sequencing libraries were quantified using qPCR Library Quantification kits (Roche, \#KK4824).

We sequenced these annotation libraries in paired end configuration with $250 \mathrm{bp}$ read length on two lanes of an Illumina HiSeq 2500 instrument. At this read length, both of the paired reads covered the barcode and the associated oligo entirely. This configuration aided in distinguishing 
sequencing errors, which are present on only one of the paired reads, from synthesis and PCR errors in the sequenced molecule and are therefore present in both paired reads. Paired reads were merged using PEAR (Zhang et al., 2014) using parameters -v 75 -m 250 -j 8 -y $2 \mathrm{G}-\mathrm{c} 40$-b 64 . Between $75 \%$ and $85 \%$ of read pairs were merged successfully.

We retained merged reads that contained two invariant sequences expected to be present in wellformed sequencing reads: in between the oligo and the barcode (TSS:

CCTGCAGGGGTTTAGCCGGCGTG; Upstream: CCTGCAGGGTTCCGCAGCCACAC; these correspond to the AscI, p2, and SbfI sequences; Figure S3, Table S11) and upstream of the oligo (GGCCGTAATGGCC in both libraries; corresponding to the SfiI-A site included in the synthetic oligo sequences; Figure S3, Table S11). These invariant sequences were used to locate the positions of the barcode and oligo in each read. This filter retained $\sim 170$ million reads in the TSS library and $\sim 125$ million reads in the Upstream library, representing 24 million (TSS) and 46 million (Upstream) unique barcodes. Most of these unique barcodes were rare (Figure S4), as indicated by median read counts per barcode of two (TSS) and one (Upstream). We did not group barcodes with similar sequences at this stage.

We examined barcodes that appeared to tag multiple oligos and concluded that the overwhelming majority of barcodes tagged a single oligo. Specifically, for the overwhelming majority of cases apparent tagging of multiple oligos, a single "primary" oligo dominated the barcode, usually making up at least $90 \%$ of oligo reads for the barcode. Examination of the "secondary" oligos showed that these usually differed from the primary oligo by a single nucleotide, most often involving a skipped base. Because our paired-end sequencing strategy reduced sequencing errors, we deemed it likely that these secondary oligos arose as PCR errors during barcoding or Illumina sequencing library generation. In downstream analyses, we only considered the primary oligo as the oligo tagged by the given barcode.

We next mapped these primary oligos to our designed sequences. Synthesis and PCR errors result in oligos that do not match the designed sequences perfectly. Because our interest was in the effects of individual sequence variants that usually alter just a single nucleotide, errors in the oligo molecules run the risk of dominating the modest effects exerted by natural regulatory variants. Therefore, we retained only barcodes for which the primary oligo perfectly matched a designed oligo. In the TSS library, we retained 9.2 million barcodes (38\% of unique barcodes), while in the Upstream library we retained 20 million barcodes $(43 \%)$.

In the TSS library, these barcodes tagged 6,565 oligos, which was $91 \%$ of all designed TSS oligos. In the Upstream library, the barcodes tagged 9,646 oligos, representing $98 \%$ of the design. Examination of designed oligos that were not present in the cloned libraries revealed that oligos starting with a guanine had lower representation in the library (Figure S5), especially for oligos that started with two guanines. This technical bias was more apparent in the TSS library, in which a higher fraction of oligos started with disfavored nucleotides than in the Upstream library.

Raw data and barcode assignments to oligos are available under GEO accession GSE155944 (https://www.ncbi.nlm.nih.gov/geo/query/acc.cgi?acc=GSE155944 ).

\section{Reporter subcloning}


After plasmid library generation, the fluorescent reporter gene was subcloned in between the promoter fragments and the barcodes of the annotated plasmid libraries by restriction digestion and ligation. Specifically, we used a codon-optimized yEGFP based on sequence from plasmid pKT0127 (Addgene plasmid \#8728; https://www.addgene.org/8728/). In the Upstream library, the 100 bases upstream of the HIS3 gene (Table S11) were included as an invariant minimal promoter between the oligo library and yEGFP, as in (Sharon et al., 2012). yEGFP and the HIS3 minimal promoter sequences were synthesized by Genewiz and were amplified using primers orc362_yeGFP (TSS) or orc362_HIS3 (Upstream), and orc363. These sequences were subcloned into the base plasmid (RCP83) to generate the final reporter plasmids.

Reporter gene inserts and the barcode-mapped plasmid library were digested as follows. We mixed $20 \mu \mathrm{g}$ of insert or $15 \mu \mathrm{g}$ plasmid library with $5 \mu \mathrm{L}$ AscI (NEB R0558L), $5 \mu \mathrm{L}$ SbfI-HF (NEB R3642L), $50 \mu \mathrm{L}$ 10x CutSmart NEB buffer, and water to $500 \mu \mathrm{L}$. These mixtures were incubated at room temperature for $2 \mathrm{~h}$ (insert) or $4 \mathrm{~h}$ (plasmid library). The library plasmids were cooled to room temperature. We added $10 \mu \mathrm{L} \mathrm{rSAP}\left(\mathrm{NEB} \# \mathrm{M} 0371 \mathrm{~L}\right.$ ) and incubated at $37^{\circ} \mathrm{C}$ for $1 \mathrm{~h}$ to prevent plasmid re-ligation. Digests were gel purified on $2 \%$ (insert) agarose or $0.8 \%$ (plasmid library), and bands at $700 \mathrm{bp}$ (insert) or $6 \mathrm{~kb}$ (plasmid library) cut and purified using QiaQuick Gel Extraction Kit (Qiagen \#28706) with elution into $30 \mu \mathrm{L}$ EB.

Ligation of the digested reporter gene into the digested library plasmids was performed by mixing $2 \mu \mathrm{g}$ (TSS) or $1 \mu \mathrm{g}$ (Upstream) of vector, $700 \mathrm{ng}$ (TSS) or $233 \mathrm{ng}$ (Upstream) of insert, $80 \mu \mathrm{L}$ of 10x T4 DNA ligase buffer, $8 \mu \mathrm{L}$ of T4 DNA ligase (NEB \#M0202M), and water to 800 $\mu \mathrm{L}$. The mixture was incubated at $16^{\circ} \mathrm{C}$ for $18 \mathrm{~h}, 65^{\circ} \mathrm{C}$ for $20 \mathrm{~min}$, and held at $12^{\circ} \mathrm{C}$. The reaction was cleaned up and eluted in $25 \mu \mathrm{L}$ water using the Zymo DNA clean and concentrator kit.

The ligated reactions were transformed into E. coli as described above for first step cloning, with 11 parallel transformations per library. Yields were 33 million (TSS) and 1.9 million (Upstream) cells per mL. Per library, $10 \mathrm{~mL}$ transformation mix were plated on twenty $15 \mathrm{~cm} \mathrm{LB}+$ carbenicillin plates, grown overnight at $30^{\circ} \mathrm{C}$, and harvested by scraping in $5 \mathrm{~mL}$ LB per plate. From the resulting dense cell mix, we grew 2 billion cells in $100 \mathrm{~mL} \mathrm{LB}+$ carbenicillin medium at $30^{\circ} \mathrm{C}$ for $\sim 20 \mathrm{~h}$ for plasmid isolation. We condensed $45 \mathrm{~mL}$ of cells into $4 \mathrm{~mL}$ aliquots of $30 \%$ glycerol.

For the TSS library, we grew one aliquot overnight in $400 \mathrm{~mL} \mathrm{LB}+$ carbenicillin medium at $30^{\circ} \mathrm{C}$ and performed three maxi preps and two mega preps (200 $\mathrm{mL}$ each) using Qiagen Plasmid Plus Purification kits (Qiagen \#12963, \#12965, \#12981). For the Upstream library, we sent glycerol stocks for large-scale plasmid prep (Genewiz) yielding $491 \mu \mathrm{g}$ of plasmid library.

Library integrity was confirmed by restriction analysis with AscI and SbfI-HF. We also created next-generation sequencing libraries targeting the barcodes as described below and sequenced them on an Illumina MiSeq instrument to confirm that the libraries had retained high barcode complexity after subcloning.

\section{Yeast strain and media}

We used a prototrophic yeast laboratory strain BY (MATa) without resistance cassettes (YLK1879) (Bloom et al., 2013). 
YNB (MSG) + glucose + G418 medium was prepared as follows: dissolve $6.7 \mathrm{~g}$ YNB without amino acids and without $\mathrm{NH}_{4} \mathrm{SO}_{4}$ and $1 \mathrm{~g}$ monosodium glutamate in $900 \mathrm{~mL} \mathrm{H}_{2} \mathrm{O}$, autoclave, let

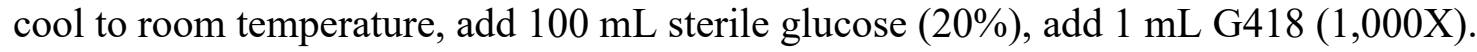

YPD medium was made by combining 5 g yeast extract (Fisher \#212720), $10 \mathrm{~g}$ peptone (Fisher \#211820), and $435 \mathrm{~mL}$ milliQ water, autoclaving, and adding $50 \mathrm{ml} 20 \%$ glucose (Fisher \#901521).

\section{Yeast transformation}

The libraries were transformed into using the LiAc method (Gietz and Schiestl, 2007). For the TSS library, we transformed 1.6 L of yeast growing in YPD at an $\mathrm{OD}_{600}$ of 1.25 with $248 \mu \mathrm{g}$ plasmid DNA. We split the $1.6 \mathrm{~L}$ culture in half, harvested by centrifugation at 3,000 $\mathrm{g}$ for $5 \mathrm{~min}$ at $20^{\circ} \mathrm{C}$, washed twice with water (once with half and once with $1 / 5$ of the culture volume), and pelleted by centrifugation. Each of the two cell pellets was mixed with transformation mix (28.8 $\mathrm{mL}$ PEG 50\% w/v, $4.32 \mathrm{~mL}$ LiAc 1M, $6 \mathrm{~mL}$ single-stranded carrier DNA at $2 \mathrm{mg} / \mathrm{mL}$, water to $43.2 \mathrm{~mL}$, as well as half the plasmid DNA) in a $50 \mathrm{~mL}$ conical tube. Prior to making the transformation mix, single-stranded carrier DNA was denatured for $5 \mathrm{~min}$ in a boiling water bath and chilled on watery ice. Transformation mix was kept on ice until use. Cells mixed with transformation mix were heat shocked at $42^{\circ} \mathrm{C}$ for $60 \mathrm{~min}$ in a shaking water bath. To recover the cells, we poured the transformation mixture into $1 \mathrm{~L}$ YPD medium pre-warmed to $30^{\circ} \mathrm{C}$ and shook them at $30^{\circ} \mathrm{C}$ for $4 \mathrm{~h}$. Recovered cells were spun at 5,000 g for $5 \mathrm{~min}$, the liquid decanted, and the pellet resuspended in $8 \mathrm{~mL}$ PBS buffer. We plated the mixture on fourteen $150 \times 15 \mathrm{~mm}$ plates (Fisher \#08-757-14; $500 \mu \mathrm{L}$ YPD + G418 per plate) and grew the cells at $30^{\circ} \mathrm{C}$ for $2 \mathrm{~d}$. A dilution series plated in parallel indicated 1.16 million cells per $500 \mu \mathrm{L}$ plated cells, for a total of 16.2 million yeast transformants.

Plates were scraped with $5 \mathrm{~mL}$ PBS per plate, the harvested cells combined, spun $(3,000 \mathrm{rpm}$ for $5 \mathrm{~min}$ ), and resuspended in $30 \mathrm{~mL}$ PBS. This cell suspension had an $\mathrm{OD}_{600}$ of 128, as estimated by measuring a dilution series. We inoculated 400 million cells $(104 \mu \mathrm{L})$ in $250 \mathrm{~mL}$ YNB (MSG) + glucose $+\mathrm{G} 418$ medium, grew them at $30^{\circ} \mathrm{C}$ for $26 \mathrm{~h}$, measured $\mathrm{OD}_{600}$, and stored aliquots ( $750 \mu \mathrm{L}$ culture in $750 \mu \mathrm{L} 40 \%$ glycerol) at $-80^{\circ} \mathrm{C}$. Each aliquot contained $\sim 60$ million cells.

The Upstream library was processed similarly, with the following differences. Transformation was performed using $320 \mu \mathrm{g}$ of plasmid DNA and resulted in a total of 67 million transformants. About 100 OD units were harvested from the plates, and 1 billion cells $(133 \mu \mathrm{L})$ grown overnight. Stored aliquots from this culture contained 250 million cells in $500 \mu \mathrm{L}$.

\section{Yeast growth}

Samples were processed using two different sets of protocols. Briefly, the initial six TSS replicates were processed at smaller scale and with two-step PCR reactions. Below, this protocol is called "Protocol 1". The remaining TSS samples and all Upstream samples were processed at larger scale and using one-step PCR reactions ("Protocol 2"). See Table S2 for further details on each sample.

\section{Protocol 1}


Aliquots of the glycerol stocks prepared during yeast transformation were thawed, spun down, the liquid removed, and the cells resuspended in $1 \mathrm{~mL}$ of YNB (MSG) + glucose + G418 medium. Resuspended cells were added to $100 \mathrm{~mL}$ medium per replicate and grown at $30^{\circ} \mathrm{C}$ to an $\mathrm{OD}_{600}$ of $0.4-0.5$. At this OD, we harvested 50 million cells for DNA prep and 100 million cells for RNA prep, assuming 30 million cells per $1 \mathrm{~mL}$ culture at $\mathrm{OD}_{600}=1$. Cells were spun down $(5 \mathrm{~min}$ at $5,000 \mathrm{~g})$, supernatant removed, and pellets placed on ice and stored at $-80^{\circ} \mathrm{C}$ as quickly as possible.

\section{Protocol 2}

Aliquots of 500 million cells were inoculated in $650 \mathrm{~mL}$ of growth medium and grown to $\mathrm{OD}_{600}$ $=0.4$. From each replicate, we collected five pellets each from 40 to $50 \mathrm{~mL}$ of culture $(\sim 500$ million cells each) for RNA extraction, and three to four pellets of $1-2 \mathrm{~g}$ of yeast for DNA extraction.

\section{DNA extraction}

\section{Protocol 1}

DNA was extracted using the Qiaprep Spin Miniprep kit (Qiagen, \#27106) combined with an inhouse yeast lysis protocol. To each sample of 50-60 million cells, we added $10 \mathrm{U}$ zymolyase in $800 \mu \mathrm{L}$ Y1 buffer (dissolve $182.2 \mathrm{~g}$ Sorbitol (Sigma Aldrich, \#S6021) in $600 \mathrm{~mL}$ water, add 200 $\mathrm{mL}$ 0.5M Na 2 EDTA, $\mathrm{pH} 8$ solution (Ambion, \#AM9262), add $1 \mathrm{~mL} 14.3 \mathrm{M} \beta$-mercaptoethanol (Sigma Aldrich, \#M3148), adjust to $1 \mathrm{~L}$ with water) and lysed the cells at $30^{\circ} \mathrm{C}$ for $30 \mathrm{~min}$ in a Thermomixer at $750 \mathrm{rpm}$. Cells stripped off their cell walls were spun for $10 \mathrm{~min}$ at $300 \mathrm{~g}$, and the supernatant removed. The remaining steps followed the Qiagen protocol. DNA was quantified using Qubit dsDNA HS assays (ThermoFisher \#Q32854).

\section{Protocol 2}

DNA was extracted from 1 to $2 \mathrm{~g}$ of yeast using the Qiagen Plasmid Plus Midi kit, following a user-supplied Qiagen protocol ("QP11.doc Aug-01" available from Qiagen). We performed two $200 \mu \mathrm{L}$ elutions. DNA was further purified and concentrated using bead clean-up (Kapa; \#KK8001) and eluted in $50 \mu \mathrm{L}$ TE buffer.

\section{RNA extraction}

\section{Protocol 1}

Total RNA was extracted from 100 million cell aliquots using the Zymo Research Fungal/Bacterial RNA Miniprep kit (ZR, \#R2014) including DNase I treatment. Bead beating was performed on a mini bead beater (Biospec). mRNA was purified using the Dynabeads mRNA Purification kit (Ambion \#61006) and eluted in $10 \mu \mathrm{L}$ of water. Total RNA and mRNA were quantified using the Qubit RNA BR kit.

\section{Protocol 2}


Total RNA was extracted using the Qiagen RNeasy Maxi Kit, with bead beating in 96-well format on the mini bead beater and on-column DNAse digestion. Total RNA was concentrated using Amicon Ultra-0.5 filter columns (Millipore \#UFC503024).

\section{DNA sequencing library construction}

\section{Protocol 1}

We used PCR to amplify the barcodes from the extracted plasmids and to generate Illumina TruSeq-compatible sequencing libraries. The resulting libraries all carried the same i5 index (which we did not sequence) and sample-specific i7 indexes that allowed multiplexed sequencing. Library generation was performed as two PCRs (Figure S6). The first PCR used universal primers (without Illumina indexes) to amplify the barcodes. Each reaction contained 7.5 - $10 \mathrm{ng}$ of plasmid DNA, $10 \mu \mathrm{L}$ of Phusion polymerase buffer, $1 \mu \mathrm{L}$ dNTPs $(10 \mathrm{mM}$; Invitrogen \#18427013), $0.25 \mu \mathrm{L}$ primer "common_ORF_v4" $(100 \mu \mathrm{M}), 0.25 \mu \mathrm{L}$ primer "RT_PCR_R_long" $(100 \mu \mathrm{M}), 0.5 \mu \mathrm{L}$ Phusion HotStart II HF Polymerase, and water to $50 \mu \mathrm{L}$. Cycling conditions were $98^{\circ} \mathrm{C}$ for $30 \mathrm{~s}, 15$ cycles of $98^{\circ} \mathrm{C}$ for $10 \mathrm{~s}, 55^{\circ} \mathrm{C}$ for $30 \mathrm{~s}, 72^{\circ} \mathrm{C}$ for $15 \mathrm{~s}$, and a final extension at $72^{\circ} \mathrm{C}$ for 5 min followed by a hold at $8^{\circ} \mathrm{C}$. Reactions were cleaned up using Qiagen PCR purification kits, eluted in $30 \mu \mathrm{L} \mathrm{EB}$, and quantified with Qubit HS DNA kits.

The $2^{\text {nd }}$ PCR added sample-specific indexed primers. We adjusted the product of the first PCR to $25 \mathrm{ng}$ in $10 \mu \mathrm{L}$, and assembled the same reaction mix as for the first PCR but with different primers: a sample-specific "RT_PCR_D7xx_F" primer and the common "Illumina_PCR_R" primer. The reaction was performed as above, but for 6 cycles and quantified with $\bar{Q}$ ubit $\overline{H S}$ DNA kits.

\section{Protocol 2}

We performed two-step PCR as above, with the following changes. Instead of Phusion, we used KAPA amplification mix (KK2602) for a reaction containing $25 \mu \mathrm{L} 2 \mathrm{X}$ KAPA mix, $5 \mu \mathrm{L}$ DNA, $19.5 \mu \mathrm{L}$ water, $0.25 \mu \mathrm{L}$ “common_ORF_v2" $(100 \mu \mathrm{M})$, and $0.25 \mu \mathrm{L}$ primer "RT_PCR_R_long" $(100 \mu \mathrm{M})$. Cycling conditions, cleanup, quantification and adjustment to $25 \mathrm{ng} / \bar{\mu} \mathrm{L}$ were the same as in Protocol 1. For the $2^{\text {nd }}$ PCR, we performed two reactions per sample, which were then combined. For Upstream samples, we performed eight parallel reactions, in order to use the entire sample. PCR conditions were the same as for the second step PCR in Protocol 1, but with $1 \mu \mathrm{L}$ of DNA and $23.5 \mu \mathrm{L}$ water. Before pooling, individual samples were quantified using qPCR Library Quantification (KAPA, \#KK4824).

For the 2018 Upstream samples (Table S2), we performed single step PCR on the DNA samples using the same reaction mix as in the $1^{\text {st }}$ step PCR above, but with primers

"RT_PCR_F_longD7xx" and "RT-PCR-R-long". PCR conditions were as above for the $1{ }^{\text {st }}$ PCR, but with $1 \overline{5}$ cycles.

RNA sequencing library construction 


\section{Protocol 1}

First-strand cDNA was synthesized by priming off the PS3 site immediately downstream of the barcodes. We combined $500 \mathrm{ng}$ of mRNA in $4 \mu \mathrm{L}$ water, $1 \mu \mathrm{L}$ primer "RT_PCR_R_long" (20 $\mu \mathrm{M}), 1 \mu \mathrm{L}$ dNTPs $(10 \mathrm{mM}$; Invitrogen \#18427013), and $8.5 \mu \mathrm{L}$ water, melted mRNA structure by incubating at $65^{\circ} \mathrm{C}$ for $5 \mathrm{~min}$, and placed the mixture on ice. We added $4 \mu \mathrm{L} 5 \mathrm{X}$ reverse transcriptase buffer, $0.5 \mu \mathrm{L}$ RiboLock RNAse inhibitor (ThermoFisher EO0381), and $1 \mu \mathrm{L}$ Maxima Reverse Transcriptase (ThermoFisher EP0742), and incubated at $30^{\circ} \mathrm{C}$ for $30 \mathrm{~min}$ and $85^{\circ} \mathrm{C}$ for $5 \mathrm{~min}$. To aid downstream PCR, we dissolved the cDNA/RNA hybrid by adding $1 \mu \mathrm{L}$ ribonuclease $\mathrm{H}$ (Invitrogen 18021-014) and incubating at $37^{\circ} \mathrm{C}$ for $20 \mathrm{~min}$.

For second-strand cDNA synthesis, we performed a single extension using a forward primer that added a handle to be used in PCR. The corresponding handle for the first cDNA strand had already been added as part of the RT_PCR_R_long primer (Figure S6). We combined $5 \mu \mathrm{L}$ of cDNA, $10 \mu \mathrm{L}$ of $5 \mathrm{X}$ Phusion buffer, $1 \mu \mathrm{L}$ dNTPs (10 mM; Invitrogen \#18427013), $2.5 \mu \mathrm{L}$ primer "common_ORF_v4" $(20 \mu \mathrm{M}), 0.5 \mu \mathrm{L}$ Phusion HotStart II HF Polymerase (ThermoFisher \#F549L), and $31 \mu \mathrm{L}$ water. We ran a single extension using the following thermocycler program: $98^{\circ} \mathrm{C}$ for $30 \mathrm{~s}, 98^{\circ} \mathrm{C}$ for $10 \mathrm{~s}, 55^{\circ} \mathrm{C}$ for $30 \mathrm{~s}, 72^{\circ} \mathrm{C}$ for $15 \mathrm{~s}, 72^{\circ} \mathrm{C}$ for $5 \mathrm{~min}$, and a hold at $8^{\circ} \mathrm{C}$.

When present in a PCR reaction, the primers used above in cDNA synthesis would be capable of amplifying plasmid DNA. To prevent this, we degraded unincorporated primers by adding $5 \mu \mathrm{L}$ of exonuclease I (ThermoFisher \#EN0581), and incubating at $37^{\circ} \mathrm{C}$ for $15 \mathrm{~min}$ and at $85^{\circ} \mathrm{C}$ for 15 min. This last step at $85^{\circ} \mathrm{C}$ inactivated the exonuclease but not the Phusion enzyme that was still present in the mixture, such that we were able to use the same mixture for additional PCR. To amplify the library and add i7 index primers, we added $0.25 \mu \mathrm{L}$ primer "Illumina_PCR_R" (100 $\mu \mathrm{M})$ and $0.25 \mu \mathrm{L}$ of a sample-specific "RT_PCR_D7xx_F" primer $(100 \mu \mathrm{M})$, and amplified as follows: $98^{\circ} \mathrm{C}$ for $30 \mathrm{~s}, 18$ cycles of $98^{\circ} \mathrm{C}$ for $10 \mathrm{~s}, 55^{\circ} \mathrm{C}$ for $30 \mathrm{~s}, 72^{\circ} \mathrm{C}$ for $15 \mathrm{~s}$, and a final extension at $72^{\circ} \mathrm{C}$ for $5 \mathrm{~min}$ followed by a hold at $8^{\circ} \mathrm{C}$. The products were quantified with Qubit HS DNA kits.

\section{Protocol 2}

First-strand cDNA synthesis was performed as in Protocol 1, with the following changes. We used SuperScript IV Reverse Transcriptase (Thermo Fisher, \#18090-200) and incubated at $50^{\circ} \mathrm{C}$ for $1 \mathrm{~h}$, using $2 \mu \mathrm{M}$ "RT_PCR_R_long" primer. To eliminate total RNA and cDNA / RNA hybrids after reverse transcription, we treated each cDNA sample with $1 \mu \mathrm{L}$ RNase A (DNase and protease free, Thermo Fisher, \#12091-021) and $1 \mu \mathrm{L}$ RNase H (Thermo Fisher, \#18021071).

PCR was performed in a single step, using $5 \mu \mathrm{L} 2 \mathrm{x}$ KAPA mix (Roche, \#KK2602), $10 \mu \mathrm{L}$ cDNA, $1 \mu \mathrm{L}$ water, $0.25 \mu \mathrm{L}$ sample-specific primer "RT_PCR_F_long_D7xx" $(100 \mu \mathrm{M}), 0.25$ $\mu \mathrm{L}$ common primer "Illumina_PCR_R" $(100 \mu \mathrm{M})$. PCR was performed as in Protocol 1, but for 15 cycles. For all Upstream as well as the 2018 TSS replicates, we performed parallel PCR reactions to capture as many cDNA molecules as possible. Before pooling, individual samples were quantified using qPCR Library Quantification (Roche, \#KK4824).

\section{Pooling and sequencing}

All PCR products from a given batch, in particular those made from DNA and cDNA from the same sample, were quantified (using Qubit or qPCR, see above) and pooled to equal molarity. 
Pooled libraries were gel extracted using QiaQuick Gel Extraction kits from 2\% gels with 1\% EtBr, run alongside a 50 bp DNA ladder. The libraries were visible in sharp bands narrowly centered on $198 \mathrm{bp}$. Excised pools were eluted in $30 \mu \mathrm{L}$ EB buffer. Pooled libraries were quantified using qPCR Library Quantification (KAPA, \#KK4824).

Sequencing was performed on Illumina HiSeq 2500 instruments in "rapid mode" using 15-20\% phiX spike-in, reading $50 \mathrm{bp}$ single ends and the i7 index.

\section{Barcode counting}

Sequences were demultiplexed using a custom php script that allowed up to one mismatch between the expected and the observed index. Indexes for each sample are available in Table S2 and Table S11. In each sample, we counted the number of reads that contained a unique barcode. Only barcodes that had been previously observed in the annotation runs were retained. Barcode reads that did not perfectly match the annotation were excluded. While this also excluded reads with sequence errors that could in principle be added to the analyses, the resulting data loss was minor: across all DNA and RNA samples, a median of $85 \%$ (a range of $75 \%-90 \%$ ) of reads mapped to known barcodes. Barcode counts for technical replicates, in which multiple indexed libraries had been created from the same growth culture, were summed. As a metric for the expression driven by each promoter oligo, we considered the $\log _{2}$ ratio of summed RNA counts of all barcodes assigned to a given oligo, divided by the summed DNA counts. We used these ratios for visualization and comparison to other data, but not in significance testing (see below).

For two out of twelve TSS samples and two out of six Upstream samples, DNA counts were unavailable. We replaced these DNA counts with those from one other sample from the same batch (Table S2). In the Upstream samples, we tested three additional strategies for adressing missing DNA values: replacement with the sum of all Upstream DNA samples, replacement with the counts from the Upstream annotation run, or sample exclusion. These different treatments did influence how many variants reached statistical significance, but only very slightly altered the estimated variant effect sizes (fold-changes). Eliminating the two Upstream samples with missing DNA would have resulted in fewer significant variants than we chose to report here, presumably due to reduced power (Myint et al., 2019). Among the options that retained all samples with RNA counts, our choice of using DNA counts from another sample from the same batch resulted in the fewest significant variant effects. Thus, our treatment of missing DNA was conservative, while still allowing us to use RNA data from all available samples.

To compare the expression driven by promoter fragments to native gene expression in the genome, we computed the average expression driven by all fragments (irrespective of which allele they carried) designed from the promoter of the given gene.

Raw data and barcode counts are available under GEO accession GSE155944 (https://www.ncbi.nlm.nih.gov/geo/query/acc.cgi?acc=GSE155944 ).

\section{Statistical analyses of variant effects}

Tests for differential allele activity were performed in the "mpra" R package (Myint et al., 2019). At each variant, we performed pairwise comparisons of the expression driven by the RM allele versus that driven by the BY allele. When there were multiple variants within a promoter 
fragment assayed by the TSS library, we computed one test per variant such that the oligo carrying the RM allele for one particular variant was compared to the oligo carrying BY alleles at all variants.

We analyzed only those oligos that had summed barcode counts larger than zero in every replicate in both DNA and RNA data. After this filter, 2,427 unique variants in 1,429 promoters remained in the TSS library. In the Upstream library, 4,467 variants in 1,824 promoters remained.

We used the "sum" barcode aggregation option in mpra, as well as mpra's normalization for library size. When a variant was assayed multiple times on a given strand in the two libraries, we used the smallest $\mathrm{p}$-value and its associated fold change for downstream analyses. FDR was calculated by the mpra package (Myint et al., 2019).

\section{Comparison of variant effects and local eQTLs}

Local eQTL effects were obtained from (Albert et al., 2018). Effect sizes were expressed as log fold changes of the RM allele relative to the BY allele. Because eQTLs can span wide genomic intervals, effect sizes and LOD scores of local eQTLs can differ slightly depending on whether they are determined at the peak marker of the given local eQTL or at the location of the gene itself. To use a metric that can be applied to all genes with MPRA data irrespective of whether the gene had a significant local eQTL, we used effects and LOD scores at the gene location. Confidence intervals for Spearman's rank correlation were computed using the DescTools package (Signorell et al., 2020).

\section{Non-additive interactions}

We tested for non-additive interactions among pairs of variants assayed in the TSS library. Specifically, we assayed 342 variant pairs in promoters for which exactly two variants were present in the promoter regions assayed by the TSS library. For these variant pairs, our design included four oligos that represented all possible combinations of the two alleles at the two given variants. We retained only promoters in which all four oligos had summed barcode counts larger than zero in DNA and RNA in every replicate.

To test for interactions, we used the mpra package (Myint et al., 2019) to fit the following model: $y=\beta_{0}+\beta_{1} x_{1}+\beta_{2} x_{2}+\beta_{3} x_{1} x_{2}+\varepsilon$

In the model, $y$ is the expression driven by an oligo, $\mathrm{x}_{1}$ and $\mathrm{x}_{2}$ are indicator variables relating an observation to the given genotype, $\beta_{0}$ is the intercept, $\beta_{1}$ and $\beta_{2}$ are the additive effects of the two variants, $\beta_{3}$ is the interaction effect that we sought to test, and $\varepsilon$ is the residual error. We contrasted this model to a model without the $\beta_{3} x_{1} x_{2}$ term.

\section{Linkage disequilibrium}

Pairwise linkage disequilibrium was calculated based on genotype data from a worldwide panel of yeast isolates (Peter et al., 2018). We computed the D' and $\mathrm{r}^{2}$ linkage disequilibrium statistics 
as implemented in the "genetics" R package (Warnes et al., 2019), using the two most frequent alleles at each marker.

\section{Variant annotation for non-TF features}

We gathered 31 non-TF features to describe each variant (Table S8). Gene annotations were obtained from (Albert et al., 2018). Nucleosome scores of a given variant in the genome was based on nucleosome occupancies reported in Supplementary Table 2 of (Brogaard et al., 2012), by extending the positions of the reported nucleosome center by 72 nucleotides in both directions. Nucleosome-free regions were defined as those with no reported occupancy. The number of TATA box motifs were counted for each variant allele and its flanking sequence using the consensus TATA(A/T)A(A/T)(A/G) (Basehoar et al., 2004). Similarly, start codons were defined as occurrences of "ATG". Ancestral alleles were defined as those present in the Taiwanese soil strain EN14S01 ("standardized name": "AMH") from the highly diverged clade 17, using the genotype data from (Peter et al., 2018). We did not assign ancestral status for variants at which EN14S01 was heterozygous. Allele frequencies were obtained from genotypes in (Peter et al., 2018). PhastCons scores, which quantify nucleotide conservation across seven Saccharomyces species (Siepel et al., 2005), were obtained for the positions corresponding to our variants from the UCSC genome browser (https://genome.ucsc.edu/index.html ) (Haeussler et al., 2019).

\section{Quantifying variant effects on predicted transcription factor binding}

We obtained position weight matrices (PWMs) for 196 TFs from the ScerTF database (Spivak and Stormo, 2011). For each variant and TF, we computed how well sequences containing the variant matched the TF's PWM. Higher "TFBS scores" represent better matches between the sequence and the PWM, increasing the probability that the TF binds the given sequence.

For a given variant, we calculated TFBS scores in sliding windows of width equal to the length of the PWM, which we moved over the variant in one-base pair increments. To compute the TFBS scores, we summed the position weights from the PWM for the bases dictated by the sequence of the given window. We computed these windowed TFBS scores for the BY and the RM allele. For each allele, we retained the best (i.e. the highest) and the mean TFBS score across windows. In the text, we report results based on the absolute difference between the best TFBS scores of the two alleles. Differences between the mean TFBS scores of the two alleles yielded similar results (Table S9).

For each TF, the ScerTF database provides sequence score cutoffs, above which the given sequence is considered to be a "strong" match to the PWM. We deemed TFBS scores below these thresholds to be "weak" TFBSs. We computed TFBS scores separately for strong and weak matches. For strong TFBSs, we considered only sequence windows in which the TFBS score exceeded the sequence score cutoff. We also computed the number of strong binding sites for each TF by counting the number of windows that exceeded the cutoff. For weak TFBSs, we only considering TFBS scores below the cutoffs for each TF.

Together, these analyses yielded five metrics for how a variant is predicted to perturb the binding of a given TF: the allelic difference in (1) the best and (2) the mean TFBS score across windows 
for strong TFBSs, (3) the number of strong binding sites, (4) the best and (5) the mean TFBS score across windows for weak TFBSs.

To consider strand-specificity in variant effects on TF-binding, these five allelic TFBS metrics were computed across three strand contexts, for a total of 15 features per TF: (1) the sense (or "plus") strand, i.e. the 5' to 3' sequence of nucleotides upstream of the reporter gene; (2) the antisense (or "minus") strand, by analyzing the reverse complement of the plus strand; (3) "strand-agnostic", in which we computed the difference between the best and mean scores across windows irrespective of which strand these scores came from. Across the 196 TFs, these features comprised a total set of 2,940 features.

To obtain the aggregated TF features that summarized the 196 TF-specific sets of features, we computed the following 27 features for each variant. In each of the three strand contexts, we counted the total number of strong TFBSs changed (3 features). Separately for strong and weak binding, we also computed the maximum difference in best or mean TFBS score across all TFs (12 features), and the average difference in best or mean TFBS score across all TFs (12 features).

\section{Logistic regression tests of single features}

We used logistic regression to test if each feature influenced the classification of a variant as causal. Causal variants were defined as those variants detected at an FDR of 5\% or better. We contrasted this set to a set of non-causal variants with an unadjusted p-value larger than 0.2. Variants in between these two categories were excluded from the analyses.

Features were transformed to Z-scores using the formula:

$Z=\left(X_{i}-\mu i\right) / \sigma_{i}$

Here, $X_{i}$ is the value of the feature for variant $i$, and $\mu_{i}$ and $\sigma_{I}$ refer to the mean and standard deviation of the feature values across all variants, respectively.

We performed logistic regression for each feature using the model:

$S_{i}=\beta_{0}+\beta_{\text {library }} x_{\text {library }}+\beta_{\text {expression }} x_{\text {expression }}+\beta_{\text {featurex }} x_{\text {feature }}+\varepsilon$

Here, the response variable $S_{i}$ is a binary vector indicating whether variant $i$ is significant. We included the library a variant was measured in and the average normalized baseline expression driven by the oligos used to measure the variant as covariates in the models. $\beta_{\text {library }}$ and $\beta_{\text {expression }}$ are the effects of these two possible confounders, while $x_{1}$ and $x_{2}$ are indicator variables relating an observation to the given covariate. $\beta_{0}$ is the overall intercept, and $\varepsilon$ is the residual error. $\beta_{\text {feature }}$ is the effect of the given feature on the probability that a variant is significant.

We used ANOVA to contrast this model to one without the $\beta_{\text {feature }} x_{\text {feature }}$ term. We corrected for multiple testing by computing FDR as q-values using the 'qvalue' package (Storey and Tibshirani, 2003).

\section{Multiple regression models}

To build predictors of variant causality ('causal' vs 'non-causal'), we first divided our set of features into 112 partially redundant feature subsets. These 112 models differed in whether they considered the non-TF features, whether they included TF features from the plus, minus, and / or 
the strand agnostic set, whether they considered strong and / or weak TF metrics, whether they included the aggregated TF summary features, and whether they included only features that had been significant in the single regression analyses. Details on each model are listed in Table S10.

For each of the 112 feature subsets, we built a logistic regression model to predict variant causality. For building these models, we first divided the variants also used in single feature analyses into a training set comprising $90 \%$ of the data, and a test set comprising $10 \%$ of the data. Training was performed using repeated 10 -fold cross validation as follows. The training set was split ten times, each time considering one of ten possible non-overlapping fractions of $10 \%$ of the training set as a validation set. In each of these ten splits, we used the remaining $90 \%$ of the training set to fit the model and computed Cohen's Kappa on the given validation set. This process was repeated five times, on five different 10-fold splits of the training data. The models were trained to maximize Cohen's Kappa on the validation sets. After training, each of the 112 models was applied to the $10 \%$ test set that had been held out from training. Model accuracy for the logistic regression models was measured by the area under the receiver operator characteristic curve (AUC).

Linear regression models to predict variant effects (expressed as absolute log-fold changes) were performed using the same repeated 10-fold cross validation scheme and trained to minimize the root-mean squared error (RMSE). Prediction accuracy was measured using Spearman correlation coefficients between predicted and actual data on the test set. All model training was done using the 'caret' package (Kuhn et al., 2020).

In the case of multiple linear regressions, we also calculated model fit as the $\mathrm{R}^{2}$ on the entire set of variants used in the single feature regressions. These linear models were fit using the ' $1 \mathrm{~m}$ ' function in $\mathrm{R}$.

Elastic net regression models predicting variant effects followed the same splitting and training strategy as for the 112 non-regularized models. We tuned the model across 10 by 10 combinations of the mixing parameter (alpha) and the regularization parameter (lambda) to select the model with the lowest RMSE in cross-validation. The best model was used to predict on the $10 \%$ test set, and model accuracy was measured as above. Elastic nets were trained using the 'caret' package (Kuhn et al., 2020).

\section{Predicting variant effects on our data using the deBoer model}

To predict gene expression corresponding to our variants, we used the non-positional YPD model with pTpA embedding from (de Boer et al., 2020). Among the models trained in that study, this model is least sensitive to the surrounding sequence context, which differs between our sequences and those used by de Boer et al. We used the model trained in YPD medium; the same medium we used in our experiments. The model uses $110 \mathrm{bp}$ of promoter sequence as input to predict gene expression. Because our oligos were $144 \mathrm{bp}$ long, we could not use the complete oligo sequence for prediction. Instead, we used $110 \mathrm{bp}$ of DNA centered on each variant. For each variant, we used two 110 bp sequences, one containing the BY allele and the other containing the RM allele. The sequences were one-hot encoded using code from de Boer et al. and then fed into the model.

The predicted expression values for the BY and RM alleles of each variant were subtracted to predict fold change between alleles. Predicted expression and variant effects were compared to 
those observed in our experiments. As observed oligo expression values, we used the 'AveExpr' value in Table S8 as the expression of the BY allele, and the sum of the 'AveExpr' and 'logFC' as the expression of the RM allele. The ' $\operatorname{logFC}$ ' was used as the observed variant effect. 


\section{Supplementary tables}

Table S1 - Oligo design

Table S2 - Information on replicate samples

Table S3 - Oligo counts per replicate

Table S4 - Statistical tests for each variant. Results for the TSS and Upstream libraries are in separate worksheets.

Table S5 - Statistical results for each variant after aggregating across the two sub libraries. Source data for Figure 2.

Table S6 - Local eQTLs and variant results. Source data for Figure 3.

Table S7 - Results from the test for epistatic interactions. Source data for Figure 4.

Table S8 - Non-TF features for each variant, along with statistical results for each variant

Table S9 - Single-feature regression analyses of causal variants. Logistic and linear regression (to predict log fold change) are in separate worksheets. Source data for Figure 5.

Table S10 - Multiple-feature regression analyses of causal variants. Logistic and linear regression (to predict log fold change) are in separate worksheets. Source data for Figure 6.

Table S1 1 - Primers sequences and sequences of various components of the reporter gene construct

\section{Supplementary files}

File S1 - All features used in variant annotation, including TFBS. (gzipped text file)

File S2 - BY/RM sequence variants used in MPRA design (gzipped vcf file)

File S3 - Sequence and map of RCP83 plasmid backbone

\section{Acknowledgements}

We are grateful to Joshua Bloom, Chad Myers, and Henry Ward for input on data analysis. We thank Carl DeBoer for help with applying his gene expression prediction model, Joshua Bloom for providing the BY / RM genotype data, and Liangke Gou for help with nucleosome data. We thank Suhua Feng for assistance with Illumina sequencing. We acknowledge resources and support from the Minnesota Supercomputing Institute.

\section{Funding}

This work was supported by NIH grant R35GM124676, a Sloan Research Fellowship (FG-201810408), and a Pew Scholarship in the Biomedical Sciences from the Pew Charitable Trusts to FWA, the Howard Hughes Medical Institute and NIH grant R01GM102308 to LK, and awards to SK from the NIH (DP2GM114829), the Searle Scholars Program, and U.S. Department of Energy (DE-FC02-02ER63421). 


\section{References}

Albert FW, Bloom JS, Siegel J, Day L, Kruglyak L. 2018. Genetics of trans-regulatory variation in gene expression. eLife 7:e35471.

Albert FW, Kruglyak L. 2015. The role of regulatory variation in complex traits and disease. Nature Reviews Genetics 16:197-212.

Albert FW, Muzzey D, Weissman JS, Kruglyak L. 2014a. Genetic Influences on Translation in Yeast. PLoS Genetics 10:e1004692.

Albert FW, Treusch S, Shockley AH, Bloom JS, Kruglyak L. 2014b. Genetics of single-cell protein abundance variation in large yeast populations. Nature 506:494-497.

Arensbergen J van, Pagie L, FitzPatrick VD, Haas M de, Baltissen MP, Comoglio F, Weide RH van der, Teunissen H, Võsa U, Franke L, Wit E de, Vermeulen M, Bussemaker HJ, Steensel B van. 2019. High-throughput identification of human SNPs affecting regulatory element activity. Nat Genet 51:1160-1169. doi:10.1038/s41588-019-0455-2

Arnold CD, Gerlach D, Stelzer C, Boryń ŁM, Rath M, Stark A. 2013. Genome-Wide Quantitative Enhancer Activity Maps Identified by STARR-seq. Science 339:1074-1077. doi:10.1126/science. 1232542

Basehoar AD, Zanton SJ, Pugh BF. 2004. Identification and Distinct Regulation of Yeast TATA Box-Containing Genes. Cell 116:699-709. doi:10.1016/S0092-8674(04)00205-3

Battle A, Mostafavi S, Zhu X, Potash JB, Weissman MM, McCormick C, Haudenschild CD, Beckman KB, Shi J, Mei R, Urban AE, Montgomery SB, Levinson DF, Koller D. 2014. Characterizing the genetic basis of transcriptome diversity through RNA-sequencing of 922 individuals. Genome Research 24:14-24.

Bloom JS, Ehrenreich IM, Loo WT, Lite T-LV, Kruglyak L. 2013. Finding the sources of missing heritability in a yeast cross. Nature 494:234-237.

Bloom JS, Kotenko I, Sadhu MJ, Treusch S, Albert FW, Kruglyak L. 2015. Genetic interactions contribute less than additive effects to quantitative trait variation in yeast. Nature Communications 6:8712.

Brem RB, Storey JD, Whittle J, Kruglyak L. 2005. Genetic interactions between polymorphisms that affect gene expression in yeast. Nature 436:701-703.

Brem RB, Yvert G, Clinton R, Kruglyak L. 2002. Genetic Dissection of Transcriptional Regulation in Budding Yeast. Science 296:752-755.

Brion C, Lutz S, Albert FW. 2020. Simultaneous quantification of mRNA and protein in single cells reveals post-transcriptional effects of genetic variation. bioRxiv 2020.07.02.185413. doi:10.1101/2020.07.02.185413

Brogaard K, Xi L, Wang J-P, Widom J. 2012. A map of nucleosome positions in yeast at basepair resolution. Nature 486:496-501. doi:10.1038/nature11142

Cambray G, Guimaraes JC, Arkin AP. 2018. Evaluation of 244,000 synthetic sequences reveals design principles to optimize translation in Escherichia coli. Nature Biotechnology 36:1005-1015. doi:10.1038/nbt.4238

Chang J, Zhou Y, Hu X, Lam L, Henry C, Green EM, Kita R, Kobor MS, Fraser HB. 2013. The Molecular Mechanism of a Cis-Regulatory Adaptation in Yeast. PLoS Genetics 9:e1003813.

Cherry JM, Hong EL, Amundsen C, Balakrishnan R, Binkley G, Chan ET, Christie KR, Costanzo MC, Dwight SS, Engel SR, Fisk DG, Hirschman JE, Hitz BC, Karra K, Krieger 
CJ, Miyasato SR, Nash RS, Park J, Skrzypek MS, Simison M, Weng S, Wong ED. 2012. Saccharomyces Genome Database: the genomics resource of budding yeast. Nucleic Acids Research 40:D700-D705.

Cheung R, Insigne KD, Yao D, Burghard CP, Wang J, Hsiao Y-HE, Jones EM, Goodman DB, Xiao X, Kosuri S. 2019. A Multiplexed Assay for Exon Recognition Reveals that an Unappreciated Fraction of Rare Genetic Variants Cause Large-Effect Splicing Disruptions. Molecular Cell 73:183-194.e8. doi:10.1016/j.molcel.2018.10.037

Choi J, Zhang T, Vu A, Ablain J, Makowski MM, Colli LM, Xu M, Rothschild H, Gräwe C, Kovacs MA, Brossard M, Taylor J, Pasaniuc B, Chari R, Chanock SJ, Hoggart CJ, Demenais F, Barrett JH, Law MH, Iles MM, Yu K, Vermeulen M, Zon LI, Brown KM. 2019. Massively parallel reporter assays combined with cell-type specific eQTL informed multiple melanoma loci and identified a pleiotropic function of HIV-1 restriction gene, MX2, in melanoma promotion. bioRxiv 625400. doi:10.1101/625400

Claussnitzer M, Dankel SN, Kim K-H, Quon G, Meuleman W, Haugen C, Glunk V, Sousa IS, Beaudry JL, Puviindran V, Abdennur NA, Liu J, Svensson P-A, Hsu Y-H, Drucker DJ, Mellgren G, Hui C-C, Hauner H, Kellis M. 2015. FTO Obesity Variant Circuitry and Adipocyte Browning in Humans. The New England journal of medicine 373:895-907. Consortium T 1000 GP. 2015. A global reference for human genetic variation. Nature 526:6874.

Costanzo M, VanderSluis B, Koch EN, Baryshnikova A, Pons C, Tan G, Wang W, Usaj M, Hanchard J, Lee SD, Pelechano V, Styles EB, Billmann M, van Leeuwen J, van Dyk N, Lin Z-Y, Kuzmin E, Nelson J, Piotrowski JS, Srikumar T, Bahr S, Chen Y, Deshpande R, Kurat CF, Li SC, Li Z, Usaj MM, Okada H, Pascoe N, San Luis B-J, Sharifpoor S, Shuteriqi E, Simpkins SW, Snider J, Suresh HG, Tan Y, Zhu H, Malod-Dognin N, Janjic V, Przulj N, Troyanskaya OG, Stagljar I, Xia T, Ohya Y, Gingras A-C, Raught B, Boutros M, Steinmetz LM, Moore CL, Rosebrock AP, Caudy AA, Myers CL, Andrews B, Boone C. 2016. A global genetic interaction network maps a wiring diagram of cellular function. Science 353:aaf1420.

Cuperus JT, Groves B, Kuchina A, Rosenberg AB, Jojic N, Fields S, Seelig G. 2017. Deep learning of the regulatory grammar of yeast 5' untranslated regions from 500,000 random sequences. Genome Res 27:2015-2024. doi:10.1101/gr.224964.117

Davis JE, Insigne KD, Jones EM, Hastings QA, Boldridge WC, Kosuri S. 2020. Dissection of cAMP Response Element Architecture by Using Genomic and Episomal Massively Parallel Reporter Assays. Cell Systems. doi:10.1016/j.cels.2020.05.011

de Boer CG, Vaishnav ED, Sadeh R, Abeyta EL, Friedman N, Regev A. 2020. Deciphering eukaryotic gene-regulatory logic with 100 million random promoters. Nature Biotechnology 38:56-65. doi:10.1038/s41587-019-0315-8

Degner JF, Pai AA, Pique-Regi R, Veyrieras J-B, Gaffney DJ, Pickrell JK, De Leon S, Michelini K, Lewellen N, Crawford GE, Stephens M, Gilad Y, Pritchard JK. 2012. DNase[thinsp]I sensitivity QTLs are a major determinant of human expression variation. Nature 482:390-394.

Dvir S, Velten L, Sharon E, Zeevi D, Carey LB, Weinberger A, Segal E. 2013. Deciphering the rules by which 5'-UTR sequences affect protein expression in yeast. PNAS 110:E2792E2801. doi:10.1073/pnas. 1222534110 
Eng KH, Kvitek DJ, Keleş S, Gasch AP. 2010. Transient Genotype-by-Environment Interactions Following Environmental Shock Provide a Source of Expression Variation for Essential Genes. Genetics 184:587-593. doi:10.1534/genetics.109.107268

Engel SR, Dietrich FS, Fisk DG, Binkley G, Balakrishnan R, Costanzo MC, Dwight SS, Hitz BC, Karra K, Nash RS, Weng S, Wong ED, Lloyd P, Skrzypek MS, Miyasato SR, Simison M, Cherry JM. 2014. The Reference Genome Sequence of Saccharomyces cerevisiae: Then and Now. G3: Genes, Genomes, Genetics 4:389-398. doi:10.1534/g3.113.008995

Farh KK-H, Marson A, Zhu J, Kleinewietfeld M, Housley WJ, Beik S, Shoresh N, Whitton H, Ryan RJH, Shishkin AA, Hatan M, Carrasco-Alfonso MJ, Mayer D, Luckey CJ, Patsopoulos NA, De Jager PL, Kuchroo VK, Epstein CB, Daly MJ, Hafler DA, Bernstein BE. 2015. Genetic and epigenetic fine mapping of causal autoimmune disease variants. Nature 518:337-343. doi:10.1038/nature13835

Forsberg SKG, Bloom JS, Sadhu MJ, Kruglyak L, Carlborg Ö. 2017. Accounting for genetic interactions improves modeling of individual quantitative trait phenotypes in yeast. Nature Genetics 49:497-503. doi:10.1038/ng.3800

Gietz RD, Schiestl RH. 2007. High-efficiency yeast transformation using the LiAc/SS carrier DNA/PEG method. Nature Protocols 2:31-34.

Gisselbrecht SS, Barrera LA, Porsch M, Aboukhalil A, Estep PW, Vedenko A, Palagi A, Kim Y, Zhu X, Busser BW, Gamble CE, Iagovitina A, Singhania A, Michelson AM, Bulyk ML. 2013. Highly parallel assays of tissue-specific enhancers in whole Drosophila embryos. Nature Methods 10:774-780. doi:10.1038/nmeth.2558

Goodman DB, Church GM, Kosuri S. 2013. Causes and Effects of N-Terminal Codon Bias in Bacterial Genes. Science 342:475-479. doi:10.1126/science.1241934

GTEx Consortium, Laboratory, Data Analysis \&Coordinating Center (LDACC)—Analysis Working Group, Statistical Methods groups-Analysis Working Group, Enhancing GTEx (eGTEx) groups, NIH Common Fund, NIH/NCI, NIH/NHGRI, NIH/NIMH, NIH/NIDA, Biospecimen Collection Source Site-NDRI, Biospecimen Collection Source Site - RPCI, Biospecimen Core Resource_-VARI, Brain Bank RepositoryUniversity of Miami Brain Endowment Bank, Leidos Biomedical_Project Management, ELSI Study, Genome Browser Data Integration \&Visualization-EBI, Genome Browser Data Integration \&Visualization-UCSC Genomics Institute, University of California Santa Cruz, Lead analysts:, Laboratory, Data Analysis \&Coordinating Center (LDACC):, NIH program management:, Biospecimen collection:, Pathology:, eQTL manuscript working group:, Battle A, Brown CD, Engelhardt BE, Montgomery SB. 2017. Genetic effects on gene expression across human tissues. Nature 550:204-213.

Haeussler M, Zweig AS, Tyner C, Speir ML, Rosenbloom KR, Raney BJ, Lee CM, Lee BT, Hinrichs AS, Gonzalez JN, Gibson D, Diekhans M, Clawson H, Casper J, Barber GP, Haussler D, Kuhn RM, Kent WJ. 2019. The UCSC Genome Browser database: 2019 update. Nucleic Acids Res 47:D853-D858. doi:10.1093/nar/gky1095

Han M, Grunstein M. 1988. Nucleosome loss activates yeast downstream promoters in vivo. Cell 55:1137-1145. doi:10.1016/0092-8674(88)90258-9

Hasin-Brumshtein Y, Khan AH, Hormozdiari F, Pan C, Parks BW, Petyuk VA, Piehowski PD, Brümmer A, Pellegrini M, Xiao X, Eskin E, Smith RD, Lusis AJ, Smith DJ. 2016. Hypothalamic transcriptomes of 99 mouse strains reveal trans eQTL hotspots, splicing QTLs and novel non-coding genes. eLife 5:3906. 
Heyne HO, Lautenschlager S, Nelson R, Besnier F, Rotival M, Cagan A, Kozhemyakina R, Plyusnina IZ, Trut L, Carlborg O, Petretto E, Kruglyak L, Pääbo S, Schoneberg T, Albert FW. 2014. Genetic Influences on Brain Gene Expression in Rats Selected for Tameness and Aggression. Genetics 198:1277-1290.

Hill WG, Goddard ME, Visscher PM. 2008. Data and theory point to mainly additive genetic variance for complex traits. PLoS Genetics 4:e1000008.

Huang Y-F, Gulko B, Siepel A. 2017. Fast, scalable prediction of deleterious noncoding variants from functional and population genomic data. Nature Genetics 49:618-624. doi:10.1038/ng.3810

Huber W, Carey VJ, Gentleman R, Anders S, Carlson M, Carvalho BS, Bravo HC, Davis S, Gatto L, Girke T, Gottardo R, Hahne F, Hansen KD, Irizarry RA, Lawrence M, Love MI, MacDonald J, Obenchain V, Oleś AK, Pagès H, Reyes A, Shannon P, Smyth GK, Tenenbaum D, Waldron L, Morgan M. 2015. Orchestrating high-throughput genomic analysis with Bioconductor. Nature Methods 12:115-121. doi:10.1038/nmeth.3252

Inoue F, Kircher M, Martin B, Cooper GM, Witten DM, McManus MT, Ahituv N, Shendure J. 2017. A systematic comparison reveals substantial differences in chromosomal versus episomal encoding of enhancer activity. Genome Res 27:38-52. doi:10.1101/gr.212092.116

Inoue F, Kreimer A, Ashuach T, Ahituv N, Yosef N. 2019. Identification and Massively Parallel Characterization of Regulatory Elements Driving Neural Induction. Cell Stem Cell 25:713-727.e10. doi:10.1016/j.stem.2019.09.010

Josephs EB, Lee YW, Stinchcombe JR, Wright SI. 2015. Association mapping reveals the role of purifying selection in the maintenance of genomic variation in gene expression. PNAS 112:15390-15395. doi:10.1073/pnas.1503027112

Kasowski M, Kyriazopoulou-Panagiotopoulou S, Grubert F, Zaugg JB, Kundaje A, Liu Y, Boyle AP, Zhang QC, Zakharia F, Spacek DV, Li J, Xie D, Olarerin-George A, Steinmetz LM, Hogenesch JB, Kellis M, Batzoglou S, Snyder M. 2013. Extensive variation in chromatin states across humans. Science 342:750-752.

Kheradpour P, Ernst J, Melnikov A, Rogov P, Wang L, Zhang X, Alston J, Mikkelsen TS, Kellis M. 2013. Systematic dissection of regulatory motifs in 2000 predicted human enhancers using a massively parallel reporter assay. Genome Research 23:800-811.

Kilpinen H, Waszak SM, Gschwind AR, Raghav SK, Witwicki RM, Orioli A, Migliavacca E, Wiederkehr M, Gutierrez-Arcelus M, Panousis NI, Yurovsky A, Lappalainen T, Romano-Palumbo L, Planchon A, Bielser D, Bryois J, Padioleau I, Udin G, Thurnheer S, Hacker D, Core LJ, Lis JT, Hernandez N, Reymond A, Deplancke B, Dermitzakis ET. 2013. Coordinated Effects of Sequence Variation on DNA Binding, Chromatin Structure, and Transcription. Science 342:744-747.

Kinney JB, Murugan A, Callan CG, Cox EC. 2010. Using deep sequencing to characterize the biophysical mechanism of a transcriptional regulatory sequence. PNAS 107:9158-9163. doi:10.1073/pnas.1004290107

Kircher M, Witten DM, Jain P, O’Roak BJ, Cooper GM, Shendure J. 2014. A general framework for estimating the relative pathogenicity of human genetic variants. Nature Genetics 46:310-315.

Kircher M, Xiong C, Martin B, Schubach M, Inoue F, Bell RJA, Costello JF, Shendure J, Ahituv N. 2019. Saturation mutagenesis of twenty disease-associated regulatory elements at 
single base-pair resolution. Nature Communications 10:1-15. doi:10.1038/s41467-01911526-w

Kita R, Venkataram S, Zhou Y, Fraser HB. 2017. High-resolution mapping of cis-regulatory variation in budding yeast. Proceedings of the National Academy of Sciences 114:E10736-E10744.

Klein JC, Keith A, Rice SJ, Shepherd C, Agarwal V, Loughlin J, Shendure J. 2019. Functional testing of thousands of osteoarthritis-associated variants for regulatory activity. Nat Commun 10:1-9. doi:10.1038/s41467-019-10439-y

Kosuri S, Goodman DB, Cambray G, Mutalik VK, Gao Y, Arkin AP, Endy D, Church GM. 2013. Composability of regulatory sequences controlling transcription and translation in Escherichia coli. Proceedings of the National Academy of Sciences 110:14024-14029.

Kotopka BJ, Smolke CD. 2020. Model-driven generation of artificial yeast promoters. Nature Communications 11:1-13. doi:10.1038/s41467-020-15977-4

Krebs AR, Dessus-Babus S, Burger L, Schübeler D. 2014. High-throughput engineering of a mammalian genome reveals building principles of methylation states at $\mathrm{CG}$ rich regions. eLife 3:e04094. doi:10.7554/eLife.04094

Kroymann J, Mitchell-Olds T. 2005. Epistasis and balanced polymorphism influencing complex trait variation. Nature 435:95-98. doi:10.1038/nature03480

Kuhn M, Wing J, Weston S, Williams A, Keefer C, Engelhardt A, Cooper T, Mayer Z, Kenkel B, R Core Team, Benesty M, Lescarbeau R, Ziem A, Scrucca L, Tang Y, Candan C, Hunt T. 2020. caret: Classification and Regression Training.

Kwasnieski JC, Fiore C, Chaudhari HG, Cohen BA. 2014. High-throughput functional testing of ENCODE segmentation predictions. Genome Research 24:1595-1602.

Kwasnieski JC, Mogno I, Myers CA, Corbo JC, Cohen BA. 2012. Complex effects of nucleotide variants in a mammalian cis-regulatory element. Proceedings of the National Academy of Sciences 109:19498-19503.

Lee D, Gorkin DU, Baker M, Strober BJ, Asoni AL, McCallion AS, Beer MA. 2015. A method to predict the impact of regulatory variants from DNA sequence. Nature Genetics 47:955-961. doi:10.1038/ng.3331

Lin Z, Wu W-S, Liang H, Woo Y, Li W-H. 2010. The spatial distribution of cis regulatory elements in yeast promoters and its implications for transcriptional regulation. $B M C$ Genomics 11.

Liu L, Sanderford MD, Patel R, Chandrashekar P, Gibson G, Kumar S. 2019. Biological relevance of computationally predicted pathogenicity of noncoding variants. Nature Communications 10:1-11. doi:10.1038/s41467-018-08270-y

Liu S, Liu Y, Zhang Q, Wu J, Liang J, Yu S, Wei G-H, White KP, Wang X. 2017. Systematic identification of regulatory variants associated with cancer risk. Genome Biology 18:194. doi:10.1186/s13059-017-1322-z

Lubliner S, Regev I, Lotan-Pompan M, Edelheit S, Weinberger A, Segal E. 2015. Core promoter sequence in yeast is a major determinant of expression level. Genome Res 25:1008-1017. doi:10.1101/gr.188193.114

Lutz S, Brion C, Kliebhan M, Albert FW. 2019. DNA variants affecting the expression of numerous genes in trans have diverse mechanisms of action and evolutionary histories. PLoS Genet 15:e1008375. doi:10.1371/journal.pgen.1008375

Mackay TFC, Stone EA, Ayroles JF. 2009. The genetics of quantitative traits: challenges and prospects. Nature Reviews Genetics 10:565-577. 
Maricque BB, Chaudhari HG, Cohen BA. 2019. A massively parallel reporter assay dissects the influence of chromatin structure on cis -regulatory activity. Nature Biotechnology 37:9095. doi:10.1038/nbt.4285

Matreyek KA, Starita LM, Stephany JJ, Martin B, Chiasson MA, Gray VE, Kircher M, Khechaduri A, Dines JN, Hause RJ, Bhatia S, Evans WE, Relling MV, Yang W, Shendure J, Fowler DM. 2018. Multiplex assessment of protein variant abundance by massively parallel sequencing. Nat Genet 50:874-882. doi:10.1038/s41588-018-0122-z

Maurer MJ, Sutardja L, Pinel D, Bauer S, Muehlbauer AL, Ames TD, Skerker JM, Arkin AP. 2017. Quantitative Trait Loci (QTL)-Guided Metabolic Engineering of a Complex Trait. ACS Synth Biol 6:566-581. doi:10.1021/acssynbio.6b00264

McVicker G, van de Geijn B, Degner JF, Cain CE, Banovich NE, Raj A, Lewellen N, Myrthil M, Gilad Y, Pritchard JK. 2013. Identification of Genetic Variants That Affect Histone Modifications in Human Cells. Science 342:747-749.

Melnikov A, Murugan A, Zhang X, Tesileanu T, Wang L, Rogov P, Feizi S, Gnirke A, Callan CG, Kinney JB, Kellis M, Lander ES, Mikkelsen TS. 2012. Systematic dissection and optimization of inducible enhancers in human cells using a massively parallel reporter assay. Nature Biotechnology 30:271-277.

Metzger BPH, Wittkopp PJ. 2019. Compensatory trans-regulatory alleles minimizing variation in TDH3 expression are common within Saccharomyces cerevisiae. Evolution Letters 3:448-461. doi:10.1002/ev13.137

Mogno I, Kwasnieski JC, Cohen BA. 2013. Massively parallel synthetic promoter assays reveal the in vivo effects of binding site variants. Genome Research 23:1908-1915.

Mulvey B, Lagunas T, Dougherty JD. 2020. The Oft-Overlooked Massively Parallel Reporter Assay: Where, When, and Which Psychiatric Genetic Variants are Functional? bioRxiv 2020.02.02.931337. doi:10.1101/2020.02.02.931337

Musunuru K, Strong A, Frank-Kamenetsky M, Lee NE, Ahfeldt T, Sachs KV, Li X, Li H, Kuperwasser N, Ruda VM, Pirruccello JP, Muchmore B, Prokunina-Olsson L, Hall JL, Schadt EE, Morales CR, Lund-Katz S, Phillips MC, Wong J, Cantley W, Racie T, Ejebe KG, Orho-Melander M, Melander O, Koteliansky V, Fitzgerald K, Krauss RM, Cowan CA, Kathiresan S, Rader DJ. 2010. From noncoding variant to phenotype via SORT1 at the 1p13 cholesterol locus. Nature 466:714-719.

Myint L, Avramopoulos DG, Goff LA, Hansen KD. 2019. Linear models enable powerful differential activity analysis in massively parallel reporter assays. BMC Genomics 20:209. doi:10.1186/s12864-019-5556-X

Newman JRS, Ghaemmaghami S, Ihmels J, Breslow DK, Noble M, DeRisi JL, Weissman JS. 2006. Single-cell proteomic analysis of S. cerevisiae reveals the architecture of biological noise. Nature 441:840-846.

Nishizaki SS, Boyle AP. 2017. Mining the Unknown: Assigning Function to Noncoding Single Nucleotide Polymorphisms. Trends in Genetics 33:34-45. doi:10.1016/j.tig.2016.10.008

Pashos EE, Park Y, Wang X, Raghavan A, Yang W, Abbey D, Peters DT, Arbelaez J, Hernandez M, Kuperwasser N, Li W, Lian Z, Liu Y, Lv W, Lytle-Gabbin SL, Marchadier DH, Rogov P, Shi J, Slovik KJ, Stylianou IM, Wang L, Yan R, Zhang X, Kathiresan S, Duncan SA, Mikkelsen TS, Morrisey EE, Rader DJ, Brown CD, Musunuru K. 2017. Large, Diverse Population Cohorts of hiPSCs and Derived Hepatocyte-like Cells Reveal Functional Genetic Variation at Blood Lipid-Associated Loci. Cell Stem Cell 20:558570.e10. doi:10.1016/j.stem.2017.03.017 
Patwardhan RP, Lee C, Litvin O, Young DL, Pe'er D, Shendure J. 2009. High-resolution analysis of DNA regulatory elements by synthetic saturation mutagenesis. Nature Biotechnology 27:1173-1175.

Pelechano V, Wei W, Steinmetz LM. 2013. Extensive transcriptional heterogeneity revealed by isoform profiling. Nature 497:127-131.

Peter J, Chiara MD, Friedrich A, Yue J-X, Pflieger D, Bergström A, Sigwalt A, Barre B, Freel K, Llored A, Cruaud C, Labadie K, Aury J-M, Istace B, Lebrigand K, Barbry P, Engelen S, Lemainque A, Wincker P, Liti G, Schacherer J. 2018. Genome evolution across 1,011 Saccharomyces cerevisiae isolates. Nature 556:339-344. doi:10.1038/s41586-018-0030-5

Rabani M, Pieper L, Chew G-L, Schier AF. 2017. A Massively Parallel Reporter Assay of 3' UTR Sequences Identifies In Vivo Rules for mRNA Degradation. Molecular Cell 68:1083-1094.e5. doi:10.1016/j.molcel.2017.11.014

Rando OJ, Winston F. 2012. Chromatin and Transcription in Yeast. Genetics 190:351-387. doi:10.1534/genetics.111.132266

Rockman MV, Skrovanek SS, Kruglyak L. 2010. Selection at Linked Sites Shapes Heritable Phenotypic Variation in C. elegans. Science 330:372-376.

Ronald J, Akey JM. 2007. The Evolution of Gene Expression QTL in Saccharomyces cerevisiae. PLOS ONE 2:e678.

Ronald J, Brem RB, Whittle J, Kruglyak L. 2005. Local Regulatory Variation in Saccharomyces cerevisiae. PLoS Genetics 1:e25.

Rosenberg AB, Patwardhan RP, Shendure J, Seelig G. 2015. Learning the Sequence Determinants of Alternative Splicing from Millions of Random Sequences. Cell 163:698-711. doi:10.1016/j.cell.2015.09.054

Safra M, Nir R, Farouq D, Slutskin IV, Schwartz S. 2017. TRUB1 is the predominant pseudouridine synthase acting on mammalian mRNA via a predictable and conserved code. Genome Res 27:393-406. doi:10.1101/gr.207613.116

Shalem O, Sharon E, Lubliner S, Regev I, Lotan-Pompan M, Yakhini Z, Segal E. 2015. Systematic dissection of the sequence determinants of gene 3' end mediated expression control. PLoS Genetics 11:e1005147.

Sharon E, Kalma Y, Sharp A, Raveh-Sadka T, Levo M, Zeevi D, Keren L, Yakhini Z, Weinberger A, Segal E. 2012. Inferring gene regulatory logic from high-throughput measurements of thousands of systematically designed promoters. Nature Biotechnology 30:521-530.

Sheff MA, Thorn KS. 2004. Optimized cassettes for fluorescent protein tagging in Saccharomyces cerevisiae. Yeast 21:661-670. doi:10.1002/yea.1130

Siepel A, Bejerano G, Pedersen JS, Hinrichs AS, Hou M, Rosenbloom K, Clawson H, Spieth J, Hillier LW, Richards S, Weinstock GM, Wilson RK, Gibbs RA, Kent WJ, Miller W, Haussler D. 2005. Evolutionarily conserved elements in vertebrate, insect, worm, and yeast genomes. Genome Res 15:1034-1050. doi:10.1101/gr.3715005

Signor SA, Nuzhdin SV. 2018. The Evolution of Gene Expression in cis and trans. Trends in Genetics 34:532-544. doi:10.1016/j.tig.2018.03.007

Signorell A, Aho K, Alfons A, Anderegg N, Aragon T, Arppe A, Baddeley A, Barton K, Bolker B, Borchers HW, Caeiro F, Champely S, Chessel D, Chhay L, Cummins C, Dewey M, Doran HC, Dray S, Dupont C, Eddelbuettel D, Enos J, Ekstrom C, Elff M, Farebrother RW, Fox J, Francois R, Friendly M, Galili T, Gamer M, Gastwirth JL, Gel YR, Gegzna V, Gross J, Grothendieck G, Jr FEH, Heiberger R, Hoehle M, Hoffmann CW, Hojsgaard 
S, Hothorn T, Huerzeler M, Hui WW, Hurd P, Hyndman RJ, Iglesias PJV, Jackson C, Kohl M, Korpela M, Kuhn M, Labes D, Lang DT, Leisch F, Lemon J, Li D, Maechler M, Magnusson A, Mainwaring B, Malter D, Marsaglia G, Marsaglia J, Matei A, Meyer D, Miao W, Millo G, Min Y, Mitchell D, Mueller F, Naepflin M, Navarro D, Nilsson H, Nordhausen K, Ogle D, Ooi H, Parsons N, Pavoine S, Plate T, Rapold R, Revelle W, Rinker T, Ripley BD, Rodriguez C, Russell N, Sabbe N, Seshan VE, Snow G, Smithson M, Soetaert K, Stahel WA, Stephenson A, Stevenson M, Stubner R, Templ M, Therneau T, Tille Y, Torgo L, Trapletti A, Ulrich J, Ushey K, VanDerWal J, Venables B, Verzani J, Warnes GR, Wellek S, Wickham H, Wilcox RR, Wolf P, Wollschlaeger D, Wood J, Wu Y, Yee T, Zeileis A. 2020. DescTools: Tools for Descriptive Statistics.

Sinha H, David L, Pascon RC, Clauder-Münster S, Krishnakumar S, Nguyen M, Shi G, Dean J, Davis RW, Oefner PJ, McCusker JH, Steinmetz LM. 2008. Sequential Elimination of Major-Effect Contributors Identifies Additional Quantitative Trait Loci Conditioning High-Temperature Growth in Yeast. Genetics 180:1661-1670.

doi:10.1534/genetics.108.092932

Smith RP, Taher L, Patwardhan RP, Kim MJ, Inoue F, Shendure J, Ovcharenko I, Ahituv N. 2013. Massively parallel decoding of mammalian regulatory sequences supports a flexible organizational model. Nature Genetics 45:1021-1028.

Spivak AT, Stormo GD. 2011. ScerTF: a comprehensive database of benchmarked position weight matrices for Saccharomyces species. Nucleic Acids Research 40:D162-D168.

Steinmetz LM, Sinha H, Richards DR, Spiegelman JI, Oefner PJ, McCusker JH, Davis RW. 2002. Dissecting the architecture of a quantitative trait locus in yeast. Nature 416:326330.

Storey JD, Tibshirani R. 2003. Statistical significance for genomewide studies. Proceedings of the National Academy of Sciences 100:9440-9445.

Stranger BE, Forrest MS, Clark AG, Minichiello MJ, Deutsch S, Lyle R, Hunt S, Kahl B, Antonarakis SE, Tavaré S, Deloukas P, Dermitzakis ET. 2005. Genome-Wide Associations of Gene Expression Variation in Humans. PLoS Genetics 1:e78.

Tanay A. 2006. Extensive low-affinity transcriptional interactions in the yeast genome. Genome Res 16:962-972. doi:10.1101/gr.5113606

Tewhey R, Kotliar D, Park DS, Liu B, Winnicki S, Reilly SK, Andersen KG, Mikkelsen TS, Lander ES, Schaffner SF, Sabeti PC. 2016. Direct Identification of Hundreds of Expression-Modulating Variants using a Multiplexed Reporter Assay. Cell 165:15191529.

Ulirsch JC, Nandakumar SK, Wang L, Giani FC, Zhang X, Rogov P, Melnikov A, McDonel P, Do R, Mikkelsen TS, Sankaran VG. 2016. Systematic Functional Dissection of Common Genetic Variation Affecting Red Blood Cell Traits. Cell 165:1530-1545.

Vockley CM, Guo C, Majoros WH, Nodzenski M, Scholtens DM, Hayes MG, Lowe WL, Reddy TE. 2015. Massively parallel quantification of the regulatory effects of noncoding genetic variation in a human cohort. Genome Research 25:1206-1214.

Wang X, He L, Goggin SM, Saadat A, Wang L, Sinnott-Armstrong N, Claussnitzer M, Kellis M. 2018. High-resolution genome-wide functional dissection of transcriptional regulatory regions and nucleotides in human. Nature Communications 9:1-15. doi:10.1038/s41467018-07746-1

Warnes G, Gorjanc with contributions from G, Leisch F, Man and M. 2019. genetics: Population Genetics. 
Weingarten-Gabbay S, Elias-Kirma S, Nir R, Gritsenko AA, Stern-Ginossar N, Yakhini Z, Weinberger A, Segal E. 2016. Systematic discovery of cap-independent translation sequences in human and viral genomes. Science 351.

Weingarten-Gabbay S, Nir R, Lubliner S, Sharon E, Kalma Y, Weinberger A, Segal E. 2019. Systematic interrogation of human promoters. Genome Res 29:171-183. doi:10.1101/gr.236075.118

West MAL, Kim K, Kliebenstein DJ, van Leeuwen H, Michelmore RW, Doerge RW, St Clair DA. 2006. Global eQTL Mapping Reveals the Complex Genetic Architecture of Transcript-Level Variation in Arabidopsis. Genetics 175:1441-1450.

Wickham H, Averick M, Bryan J, Chang W, McGowan LD, François R, Grolemund G, Hayes A, Henry L, Hester J, Kuhn M, Pedersen TL, Miller E, Bache SM, Müller K, Ooms J, Robinson D, Seidel DP, Spinu V, Takahashi K, Vaughan D, Wilke C, Woo K, Yutani H. 2019. Welcome to the Tidyverse. Journal of Open Source Software 4:1686. doi:10.21105/joss.01686

Wunderlich Z, Mirny LA. 2009. Different gene regulation strategies revealed by analysis of binding motifs. Trends in Genetics 25:434-440. doi:10.1016/j.tig.2009.08.003

Yao DW, O’Connor LJ, Price AL, Gusev A. 2020. Quantifying genetic effects on disease mediated by assayed gene expression levels. Nature Genetics 52:626-633. doi:10.1038/s41588-020-0625-2

Zhang J, Kobert K, Flouri T, Stamatakis A. 2014. PEAR: a fast and accurate Illumina Paired-End reAd mergeR. Bioinformatics 30:614-620. doi:10.1093/bioinformatics/btt593

Zheng D-Q, Wang P-M, Chen J, Zhang K, Liu T-Z, Wu X-C, Li Y-D, Zhao Y-H. 2012. Genome sequencing and genetic breeding of a bioethanol Saccharomyces cerevisiae strain YJS329. BMC Genomics 13:479. doi:10.1186/1471-2164-13-479

Zhou J, Theesfeld CL, Yao K, Chen KM, Wong AK, Troyanskaya OG. 2018. Deep learning sequence-based ab initio prediction of variant effects on expression and disease risk. Nat Genet 50:1171-1179. doi:10.1038/s41588-018-0160-6

Zhou J, Troyanskaya OG. 2015. Predicting effects of noncoding variants with deep learningbased sequence model. Nature methods 12:931-934.

Zhu F, Farnung L, Kaasinen E, Sahu B, Yin Y, Wei B, Dodonova SO, Nitta KR, Morgunova E, Taipale M, Cramer P, Taipale J. 2018. The interaction landscape between transcription factors and the nucleosome. Nature 562:76-81. doi:10.1038/s41586-018-0549-5 